\title{
DESDE LA PERSPECTIVA DE LA ISLA. GUERRA Y TRANSFORMACIÓN EN UN ARCHIPIÉLAGO VERTICAL ANDINO: MACHA (NORTE DE POTOSÍ, BOLIVIA)1
}

\author{
FROM THE ISLAND'S POINT OF VIEW. WARFARE AND \\ TRANSFORMATION IN AN ANDEAN VERTICAL ARCHIPELAGO: \\ MACHA (NORTHERN POTOSÍ, BOLIVIA)
}

Tristan Platt ${ }^{1}$

In memoriam John V. Murra (1916-2006)

\begin{abstract}
El artículo combina la teoría del "archipiélago vertical" andino propuesto por John V. Murra -un modelo dinámico de las cambiantes relaciones históricas entre las sociedades andinas, las ecologías complementarias que habitan y las formaciones "estatales" emergentes- con las teorías transformacionalistas desarrolladas para los pueblos del Amazonas. Basado en trabajo etnográfico realizado con un "archipiélago" de larga duración en los valles del Ayllu Macha (Norte de Potosí, Bolivia), este texto muestra la experiencia conflictiva de algunas "islas" vallunas, que deben invertir su pertenencia de parcialidad ("mitad", o saya) para poder persistir entre los grupos mayores que dominan su vecindad. La confusión entre los niveles de segmentación y la formación de las "islas" exigen otros patrones de alianza de las que se dan en la puna (tierras altas), a la vez que ambas regiones comparten un mismo horizonte de ideas con respecto a la violencia. La guerra andina se caracteriza por la misma "inestabilidad ontológica" en la frontera borrosa entre animales y seres humanos que ha sido encontrada en otros grupos amerindios, como también en otras partes del mundo. Se muestra que los diversos tipos de transformación y la reformulación de las fronteras entre animales y humanos deben ser relacionados con diferentes contextos sociales e históricos.
\end{abstract}

Palabras claves: Andes, archipiélago vertical, guerra, transformaciones, fronteras socio-ontológicas, etnohistorias.

The article relates John Murra's theory of the "vertical archipelago" - a dynamic model of the changing historical relations between Andean societies, the complementary ecologies they inhabit, and emergent "State"-formations to transformationalist theories developed particularly among Amazonian peoples. Drawing on field-work with a longlived "archipelago" in the valleys of the Macha Ayllu (Northern Potosí, Bolivia), the author shows the conflictive experience of valley "islands", which must invert their moiety (saya) affiliations to survive pressures from the larger groups in which they are implanted. The confusion of levels of segmentation and the "island" formation produces different valley alliances from those sought on the puna, while presupposing a shared horizon of ideas concerning violence. Andean warfare is characterized by the same "ontological instability" at the blurred frontier between humans and animals that is found among other Amerindian groups, and elsewhere in the world. Different kinds of shapeshifting during fiestas and warfare, and the reformulation of animal-human frontiers, are seen to be related to different social and historical contexts.

Key words: Andes, vertical archipelago, warfare, shapeshifting, socio-ontological frontiers, ethnohistories.

Mi propósito en este artículo es interrelacionar dos teorías, cada una de las cuales ha provocado un amplio debate pero todavía no se ha llegado a integrar la una en la otra. Una, la del "archipiélago vertical”, es un tema emblemático de John Murra: él analizó el "control vertical de un máximo de pisos ecológicos" en las sociedades andinas cuyos núcleos de poder estaban ubicados en diferentes niveles de altura; y, además, trató de comprender las implicancias sociológicas y políticas de la organización "multiétnica" en lejanos nichos de recursos (Murra 1975 [1972], 2002; Masuda et al. 1985). Este modelo ha sido considerado casi como un diagnóstico de la organización económica de los Andes centrales, y se ha dado por sentado que es irrelevante para la Amazonia (ver Uzendoski 2004). En cambio, el segundo tema, las transformaciones animales-humanas, ha sido fuertemente desarrollado en los estudios de la Amazonia (ver, p.ej., Viveiros de Castro 1998), pero sin reconocer sus posibles resonancias en la vecina región andina. La transformación de los guerreros y chamanes en animales (ya sean salvajes, khuru, o domesticados, uywa) y la oscilación de las apariencias sagradas entre lo humano y lo animal es algo que también se encuentra entre los transformistas (shapeshifters)

School of Philosophical, Anthropological and Film Studies, University of St. Andrews, St. Andrews, Scotland. tp@ @st-andrews.ac.uk 
andinos, tanto en los discursos mito-históricos como en los que tratan del presente.

Para relacionar estos dos temas recurriré a la etnografía que he levantado a partir de los años 1970-71 con el grupo étnico Macha (norte de Potosí, Bolivia) (Figura 1), el que desciende históricamente del grupo que fue la cabecera dominante entre la gran federación pre-hispánica de los Qaraqara (Platt et al. 2006). Expondré las diferencias que se dan, al momento de formar alianzas y escoger enemigos, entre las comunidades de las tierras altas (3.800-4.200 msm) y los colonos de estas mismas poblaciones asentados en los valles maiceros de Macha $( \pm 2.500 \mathrm{msm})$.

Para explicar las nuevas perspectivas que emergen en el "archipiélago" valluno, debemos situar estos colonos dentro de un horizonte más amplio y en el ethos de la guerra regional. Como en otros grupos del Norte de Potosí, en Macha una ética guerrera atraviesa la sociedad tradicional; empero, media una importante diferencia entre la "competencia equilibrada" (tinku) y la "desequilibrada destrucción" (ch'ajwa). En otro trabajo sugerí que la implantación de la pax incaica significó convertir los ch'awjas en tinkus, restringiendo así la guerra abierta y apoyando el surgimiento de "juegos" de competencia (pujllay) en intervalos regulares del ciclo ritual (Platt 1987a). Aún hoy, sin embargo, un tinku puede convertirse en un ch'ajwa, especialmente cuando se lo celebra en el campo, lejos de las pueblos parroquiales. Con todo, el vaivén entre tinkus y ch'ajwas no es simplemente un asunto de mayor o menor violencia. Un tinku puede hacer resaltar los conflictos sociales subyacentes entre los ayllus, entre las mitades y, aún más ampliamente, entre indios, mestizos (o mosos), vecinos y el Estado (representado por las autoridades pueblerinas, las policías $\mathrm{y}$, desde los años noventa, los militares). Pero un ch'ajwa puede, además, intentar una transformación radical de dichas relaciones entre los individuos, la comunidad y la sociedad más amplia. Entonces, sugeriré que busquemos relacionar los cambios de las prácticas guerreras en las sociedades sudamericanas con los sucesos históricos, a fin de reintroducir la historia en la discusión etnológica sobre las transformaciones entre humanos y animales.

Este trabajo aboga por la importancia de expandir entre sí los universos de referencia de los estudiosos de las tierras bajas y los andinistas y, más globalmente, extenderlos hacia toda la América del Sur. Una antropología de esta naturaleza contempla las transformaciones estructurales y las percepciones fenomenológicas como el fruto de las historias colectivas y personales; y es ése, precisamente, el enfoque que Murra vivió, practicó y nos urgió a seguir.

\section{Translocación y Transformación}

La alta puna está coronada por sociedades especializadas en el pastoreo que alcanzan hasta los $4.500 \mathrm{~m}$ sobre el nivel del mar (Flores 1979 [1977]; Dransart 2002). Las características tan únicas del medio andino tropical ya fueron reseñadas por Carl Troll (1968). Este autor llamó la atención hacia los recursos de gran altura que permitían el desarrollo de la civilización alto-andina. Siguiendo la senda de Troll, en los años 1960 y 1970 Murra impulsó la investigación interdisciplinaria sobre la organización vertical de las sociedades andinas de diferentes dimensiones y cuyos centros de autoridad se ubicaban en diversos pisos de altura. Así, por ejemplo, las sociedades del altiplano con una determinada economía y geografía sagrada habían optado por readaptarse a sí mismas al momento de prolongarse hacia nuevas condiciones ecológicas en alturas más bajas y cálidas. Al mismo tiempo, los colonos de abajo seguían manteniendo un acceso a las tierras frías de la puna, y a sus recursos, por intermedio de sus parientes en el altiplano.

Murra acuñó la metáfora del "archipiélago vertical" para tipificar las sociedades que brotaban de la mezcla de colonos de los diferentes grupos en los confines de la extensión política de sus sociedades nucleares, tanto hacia arriba como hacia abajo y en ambas vertientes de la cordillera, hacia el Pacífico y el Atlántico. Los colonos fueron concebidos como viviendo en algo así como "islas" en una vecindad "multiétnica", colindantes con otras "islas" colocadas allí por otros grupos 2 . Murra pensaba, además, que el reasentamiento de poblaciones por el Estado inca, los llamados mitimaes estatales, pudo concebirse como una transformación del modelo "vertical", en el cual el ideal de cada sociedad de maximizar su base de recursos era trascendido por las estrategias económicas, militares y políticas del Tawantinsuyu (Murra 2002; Presta 1995; $c f$. Saignes 1985) ${ }^{3}$.

Murra sostenía que su modelo era también aplicable a períodos "inmediatamente previos" a la emergencia de los estados andinos y que, además, encauzaba la forma de su desarrollo. 




Figura 1. Mapa con la distribución de las tierras de Macha en San Marcos de Miraflores, Potosí Bolivia (dibujado por Graeme Sandeman, cartógrafo, Universidad de St Andrews).

Map showing distribution of Macha lands in San Marcos de Miraflores, Potosí, Bolivia (drawn by Graeme Sandeman, cartographer, University of St Andrews).

Para esos "períodos intermedios" entre sucesivas formaciones estatales, predijo el descubrimiento de "redes de reclamos, ajustes temporales, tensiones, conflictos y treguas entre varios núcleos regionales que compartían el mismo ideal [de verticalidad] en una etapa inmediatamente previa a la formación de los 'horizontes' arqueológicos" (Murra 2002) 4 Ha quedado sin embargo sumida en la oscuridad la manera como esos conflictos fueron vivenciados, equilibrados y provisoriamente resueltos.

El Ayllu Macha habla hoy en día un dialecto del quechua sureño bastante influenciado por el 
español y el aymara, aunque es una derivación histórica de la unidad social que lideraba en tiempos prehispánicos la federación aymara-hablante de los "Charka Blanca", o Qaraqara. Este fue uno de los conjuntos más grandes dentro de la "provincia de Charcas" inca (ubicada hacia el sur de la actual Oruro hasta la frontera con Humahuaca). Macha siguió ejerciendo un importante protagonismo político durante los períodos colonial y republicano (Platt et al. 2006; Platt 1982a, 1991 [1984], 1987b; Serulnikov 2006). Más aún, tenemos ahora evidencias de que el "archipiélago" local de San Marcos de Miraflores (donde vivía en 1970-71) había subsistido hasta mi llegada con una sorprendente continuidad desde mucho antes del tardío siglo XVI y el temprano XVII, cuando fue observado y descrito por los primeros visitadores coloniales ${ }^{5}$.

Una parte de mi argumento tiene que ver con el lenguaje que utilizamos para hablar de la "organización social vertical". La propia frase de Murra, el "archipiélago" vertical, es una poderosa metáfora para destacar el patrón interdigitado de territorialidad discontinua ${ }^{6}$, pero también puede convertirse en una pantalla que encubre otras maneras de imaginar la situación. Parece implicar un mar con un grupo de islas a cierta distancia del más cercano continente. Ahora bien, ¿dónde está el mar?, ¿representa los límites de la tierra que media entre "islas" étnicas vecinas? ¿Significa la "región intermedia" de transición (chawpirana) que los colonos del altiplano tienen que cruzar para llegar a sus tierras en el valle? Más aún, ¿cómo hay que entender algunas situaciones en las que, como ocurre en los valles de Macha, unidades domésticas solitarias pertenecientes a un grupo o ayllu pueden estar rodeadas por un conjunto de casas que pertenecen a otro grupo, formando algo así como "pequeñas islas" dentro de "grandes islas"? Bajo esta mirada el cuadro se torna más complejo.

Veamos, entonces, cómo se habla de la "verticalidad" en quechua y aymará. ¿Qué otras expresiones hay disponibles para expresar las relaciones sociales que están detrás de la metáfora del archipiélago? Consideraremos dos "metáforas vividas por la gente" (metaphors people live by) en los Andes (para utilizar la frase sugerente de Lakoff y Johnson [1980]): la textil y la reproducción vegetal. ${ }^{7}$ Ya en 1985 Olivia Harris sugirió la comparación de la organización espacial del Norte de Potosí con la organización del espacio de los tejidos de Isluga (Chile) destacada por los trabajos de Verónica Cereceda $(1978,2010)$.
Harris sostenía que los campesinos del Norte de Potosí que viven en los niveles máximos de altura tienden a poseer sus tierras vallunas en las regiones más bajas, mientras que los que viven en la región "intermedia" (Que. chawpirana; Aym. taypirana), entre puna y valle, podían extenderse desde sus asentamientos nucleares hacia arriba y hacia abajo, en un radio de alcance relativamente reducido. Harris comparó esta distribución con la gramática espacial de los diseños textiles geométricos descubiertos por Cereceda, en los cuales las franjas simétricas en los bordes opuestos de las piezas del tejido rectangulares son puestas en contraste con la banda fértil, o "corazón”, ubicado en el centro del diseño. Las gradaciones climáticas desde frío a caliente dentro de la chawpirana pueden ser comparadas con las degradaciones cromáticas ( $k^{\prime} i s a$ ) que mediatizan entre dos colores opuestos en el "corazón" de los tejidos Isluga. Harris no argumentó en su trabajo sobre el patrón de asentamiento en "archipiélago" y está aún por demostrarse etnográficamente el acento que puso en una relativa autosuficiencia del centro (ver Mendoza y Patzi 1997, para mayores detalles). Sin embargo, la idea de un tejido social se reitera en las imágenes quechuas y aymaras de la vida "isleña" que pueden ser escuchadas en los valles de Macha. En efecto, un "isleño" con quien pude hablar en 1971 comparó su precaria situación con la de "una hebra rota", una imagen clara de separación y diferencia, que captaba a la vez la lejanía de sus compañeros de la puna y su aislamiento con respecto a sus vecinos del valle.

Otra forma de expresión del asentamiento vertical puede derivarse de los procesos de reproducción vegetal. Dos mallki-dos arbustos emparejados que encarnan una pareja ápice- pueden constatarse en varios contextos etnohistóricos (ver p.ej., Pachacuti Yamqui Salcamaygua 1993 [1613]). Esas expresiones las volvemos a encontrar en Macha, hoy en día, como dos ramitos de molle que se colocan a la cabecera de las mesas/misas rituales, como símbolos de una perenne fertilidad. Fusionados, también reaparecen como árboles que crecen frente a las iglesias en las plazas de los "pueblos de indios" (reducciones); se dice que sus raíces, divididas en masculino-femenino, se extienden para sustentar cada una de las unidades domésticas de la parroquia ( $c f$. Platt 1978; 1996, nota 15). Entonces, mientras diagramaba las conexiones verticales entre grupos de parentesco del valle y de la puna, me pregunté de qué manera las respectivas "raíces" 
de las unidades domésticas, conectadas localmente con esos árboles y torres, podían estar conectadas también a través de los declives de la cordillera. Una posible solución al problema me fue sugerida por un conocido de Macha que me contó que mallki era el nombre quechua de "aquellas plantas que arrojan otras plantas". ¿Cabría imaginar los lazos verticales como un sistema de raíces subterráneas, como los "estolones" de las plantas de fresa, o sea, tallos rastreros que se enraízan a una distancia de la planta madre? ¿Tenían los colonos que "enraizarse a sí mismos" como isleños del valle, habiendo sido enviados hacia abajo por sus grupos de parentesco asentados en la puna? ${ }^{8}$

En este artículo mostraré cómo los colonos que bajan desde la puna, al mismo tiempo que replican su organización social en los niveles de asentamiento en los pisos más abajo, a la vez introducen modificaciones en los valles que brotan de la apretada coexistencia de los diferentes niveles de segmentación social dentro de un espacio compartido. Estas adaptaciones de las organizaciones del altiplano son sorprendentemente sistemáticas; aunque abren situaciones ambiguas, sin embargo hicieron posible que las "islas" coexistieran con múltiples afiliaciones dentro de los valles intermontanos, y los hicieran habitables.

Otro rasgo importante de la región es, precisamente, una prolongada tradición de guerras entre grupos vecinos en los diferentes niveles de segmentación (Platt et al. 2006). En el caso de las "islas", la identificación de enemigos y aliados sigue diferentes criterios a los que se emplean en la puna: se define de otra manera a quiénes se puede combatir y comer, y con quiénes se comparte el frente de batalla y la comensalidad. Otros ayllus de la misma mitad pueden ser tenidos por aliados en la puna, no obstante, pueden ser recategorizados como enemigos en las islas vallunas. De la misma manera, ayllus de la otra mitad, considerados como enemigos en la puna, pueden ser tomados por aliados en el contexto del archipiélago del valle. Por consiguiente, la oposición polar entre mitades (Anansaya y Urinsaya, las mitades de "arriba" y de "abajo") resulta ser mediada por gradaciones de experiencia intermedia que dejan abierta una gama de definiciones sociales ambiguas que caracterizan las islas vulnerables del valle. Un análisis de estas diferencias entre la formación de alianzas en el altiplano y en las tierras bajas nos conducirá a la médula del archipiélago vertical.
Bien sabido es que, hoy en día, ocurren batallas rituales o tinkus en todas partes del Norte de Potosí, por lo general en los pueblos o en las aldeas, y están asociadas al calendario de las diversas fiestas católicas. Estas batallas son, entre otras cosas, rituales de confirmación del acceso de diferentes grupos a las tierras, y momentos en que las relaciones de alianza se plantean o verifican. Algunos hombres, individualmente, pueden presentarse como si fueran toros bravos que combaten entre sí para demostrar sus proezas, rivalizando con otros a gritos de borrachos: jturu kaniy, carajuuu!, “ ¡soy toro, carajo”! Los enfrentamientos estallan en las plazas y las esquinas de las calles bajo el ojo vigilante de las autoridades regionales de los pueblos y aldeas (Harris 2000; Platt 1996). En el pueblo de Macha asentado en la puna, los participantes salen por lo general de las dos parcialidades opuestas; sin embargo, más abajo en el lado oriental de la cordillera, las mitades pueden llegar a juntarse para presentar un frente Macha unificado a un grupo étnico vecino con el que comparten una misma jurisdicción parroquial (p.ej., cuando ambas parcialidades combaten juntas contra los Pocoatas en el pueblo chawpirana de Surumi). Aún más abajo, estos grupos pueden volverse aliados contra una alianza rival (en San Marcos de Miraflores, los K'ultas y los Macha Anansaya contra los Macha Urinsaya; y los Machas y Pocoatas contra los Laymis y los Purakas en el pueblo de Carasi). Conforme se desciende, los representantes locales de las clasificaciones más abarcadoras pueden suspender sus hostilidades y hacerse aliados contra un bloque rival.

Por el contrario, los enfrentamientos más feroces (ch'ajwas) se dan fuera de la mirada vigilante de las autoridades mestizas, la policía, los militares y, hoy en día, de los turistas ávidos de fuertes emociones. Si los tinkus son ya un juego violento (pujllay), las otras batallas, que ocurren cerro adentro, son consideradas como una guerra en serio: entonces, hasta los guerreros más curtidos se vuelven aprensivos. Los miembros de los ayllus y de las mitades (parcialidades, o sayas) se alinean para combatir contra sus contrincantes en batallas que suceden por los límites de las tierras: emplean hondas, provocan incendios, hacen violaciones colectivas y a veces utilizan armas de fuego. En una ocasión que observé de cerca, los guerreros eran apoyados por mujeres que cantaban y preparaban chicha detrás de la línea de batalla, esperando su retorno. En los ch'ajwas de la puna, donde las hileras de 
guerreros pueden entrar en combate con hondas o enredarse en luchas cuerpo a cuerpo, se cuenta que los hombres pueden asumir a veces la forma de animales salvajes (khuru), con lo cual los límites entre los humanos y los animales se tornan difusos e inestables. Convertidos en osos (jukumari), búhos (juku) o pumas (puma), la agresión predatoria de los combatientes que se han transmutado en animales salvajes remplaza su transformación en los tinkus, en el más bravo de los animales domesticados y criados: los toros de lidia.

La identificación social, simbólica y ritual de los indígenas norpotosinos con animales domésticos (uywas) en tiempos de paz ha sido bastante documentada (Abercrombie 1998; Stobart 2006). Durante los rituales que acompañan a la fiesta de Corpus Christi en el pueblo valluno de San Marcos, por ejemplo, los hombres se cargan los costales de las llamas (kustalas), o pieles de cabras y de corderos; también pueden convertirse en yuntas de hombres-bueyes que aran simbólicamente la plaza (se los conoce a todos, colectivamente, como jañachus, o "llamas sementales"). A su vez, los mestizos locales actúan de zorros y pumas que juguetonamente atacan a los indígenas e intentan robarles sus pieles de animales, haciendo una representación burlesca de las relaciones de fuerza locales (Platt 1996) (Figura 2). Las élites tradicionales de la sociedad rural -los hacendados y los mestizos dominantes- encarnan las fuerzas naturales, los animales y pájaros, y aún las amenazas climáticas. Como señores del relámpago y del trueno, por ejemplo, se dice que cabalgan entre las nubes con bocados de freno y estribos hechos de plata, disparando sus armas o arcabuces cuyas balas caen en la tierra como rayos (balas) que sacralizan "lugares" y propician una iniciación a los chamanes masculinos y a las parteras en las artes de su oficio (Platt 1997, 2001). El ayllu es el locus y un refugio de la sociabilidad, del cultivo agrícola y de la domesticación; en cambio, en los lugares salvajes, los animales y cualquier otro fenómeno natural son fuentes potenciales de poder sagrado que se asocia a otros tipos de "gente" allende el ayllu?"

Sin embargo, en las ch'ajwas el orden "normal" de las cosas es destruido al combatir la gente por tierras en disputa que se quieren integrar en su jurisdicción. Transformados de repente en animales salvajes los guerreros adquieren poderes sagrados, pueden llegar a descuartizar a sus adversarios, beber su sangre y devorar sus órganos -la lengua,

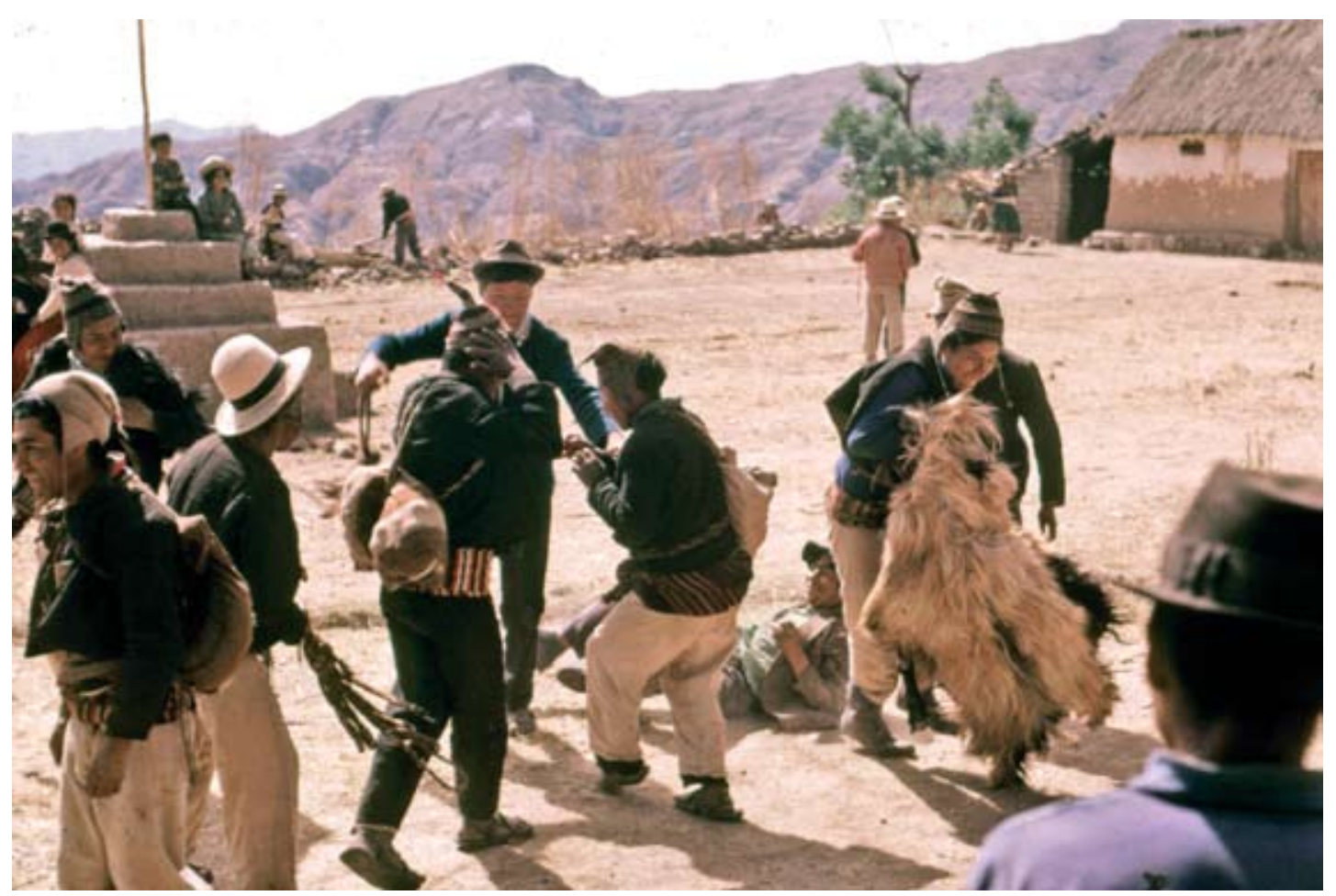

Figura 2. Mestizos de San Marcos como animales "silvestres" intentando quitar sus pieles a los indios "domesticados" (Corpus Christi 1971). San Marcos mestizos as "wild animals" trying to steal the skins of Indian "domesticated animals" (Corpus Christi, 1971). 
los ojos, el hígado, el corazón, los testículos- en actos frenéticos de exocanibalismo. De este modo, efectivamente resucita el ambiguo papel de los animales durante la antigua edad de los Chullpa, el mítico "tiempo inquieto" (inkyitu tyimpu) de los antecesores bañados por la luz lunar, antes de la aurora del Sol Inca-Hapsburgo. En aquel tiempo, los animales salvajes pudieron devenir humanos y los humanos animales salvajes (Platt 1978, 1996, 2001; cf. Stobart 2006). Guaman Poma llama a este período la "Edad de los Guerreros" (Awka Runa); y se lo ubica "antes" de la llegada de los Incas, coincidiendo con el período Intermedio Tardío descrito por Murra y otros autores como un tiempo caracterizado por tensiones extremas e inestabilidad social (cf. Guaman Poma 1980 [1615]). Las identidades oscilantes de los Chullpa durante esa "edad lunar" de combates y hostilidad recuerdan la violencia y la anarquía que impera en los ch'ajwas, cuando el orden y las fronteras son por igual suspendidos y disputados, y se quiebran las condiciones para la pacífica coexistencia. Entonces, las relaciones sociales se disuelven a medida que las ambiguas identidades de los animales chullpa vuelven a emerger y, en cada ejército, los guerreros más feroces adquieren la facultad de transfigurarse ${ }^{10}$. En los ch'ajwa las actividades del tiempo presente resucitan los tiempos míticos del pasado. Se podría afirmar, incluso, que estos combates suceden "fuera del tiempo" y "fuera de la sociedad", re-creando relaciones mitohistóricas que subyacen en la formación de la edad social presente. Visto desde otra perspectiva, sin embargo, esos combates pueden ser fechados y vinculados a la historia linear de las relaciones políticas locales, y hasta de las nacionales.

Convendría recordar aquí que, hoy en día, se dice que algunos animales salvajes, por ejemplo el puma, son los "pastores de montaña" (awatiri) de los animales domésticos, al mismo tiempo que los convierten en presas y los devoran como alimento. Asimismo, transformados en animales silvestres, los combatientes atacan a sus enemigos y se los comen, con lo cual se los convierte en animales domésticos que son víctimas de un acto predatorio. Sin embargo, los guerreros en tanto que humanos, se podría decir que sacrifican a sus enemigos, vierten su sangre en el suelo para aplacar el hambre y la ira de las deidades de la tierra. Devoran sus órganos vitales, pero entierran los restos, especialmente los cráneos (kawisas; Esp. "cabezas") como ofrendas para alimentar y calmar a las colinas y montañas hambrientas. Quizás esto pudiera sugerir una razón por la que en los Andes ha sido a menudo difícil distinguir los aspectos sacrificial y predatario de las matanzas.

Es justamente dentro de este contexto de enfrentamiento cósmico más amplio, de la guerra como "juego" y como destrucción, que las confusas circunstancias vallunas representan una situación de mediaciones y atenuantes, importantes pero poco comprendidas. Aunque integran el universo social y religioso macha más amplio, la situación de los valles exhibe características distintivas y propias, lo cual confirma la intuición que Murra destacó sobre las inestabilidades, las alianzas temporales y los conflictos que caracterizaron a los "archipiélagos" en el período Intermedio Tardío, como lugares de mezcla y de yuxtaposición multiétnica en los confines de la capacidad de las sociedades andinas de colonizar y compartir los lejanos nichos ecológicos.

\section{El Archipiélago de Macha más de cerca}

Los pastores de llamas descienden cada año desde la puna hacia los valles, por lo general entre abril y septiembre, para participar en relaciones de intercambio con parientes y otros socios en la vieja parroquia colonial (doctrina) de San Marcos de Miraflores ${ }^{11}$ (Figura 3). El trayecto a los valles toma dos semanas camino abajo arreando llamas desde la puna y 3-4 días sin llamas. Los campesinos andinos habitan su entorno atravesándolo y disputándolo en el proceso de transformarlo. A los viajeros, en tiempos de paz, el acceso a los senderos y los pastizales en común está por lo general permitido; pero cruzarlos puede ser considerado un acto de provocación cuando los conflictos por tierras han establecido contrapuestos frentes de guerra que se extienden por montes y quebradas, vigilados por sentinelas. El viaje entre la puna y los valles perpetúa una red de chaki ñan (senderos peatonales) recorridos por los campesinos que zigzaguean por el territorio vertical macha. Están señalados puntualmente por lugares ceremoniales vinculados, ya sea con los pasos (apachitas), ya sea con otras características llamativas del paisaje sacralizado. A la entrada del valle se alzan dos altos picos de montaña, uno de cada mitad: es ahí donde las autoridades de la puna solían cumplir sacrificios y verter libaciones para afianzar la relación complementaria entre las tierras altas y las bajas. 


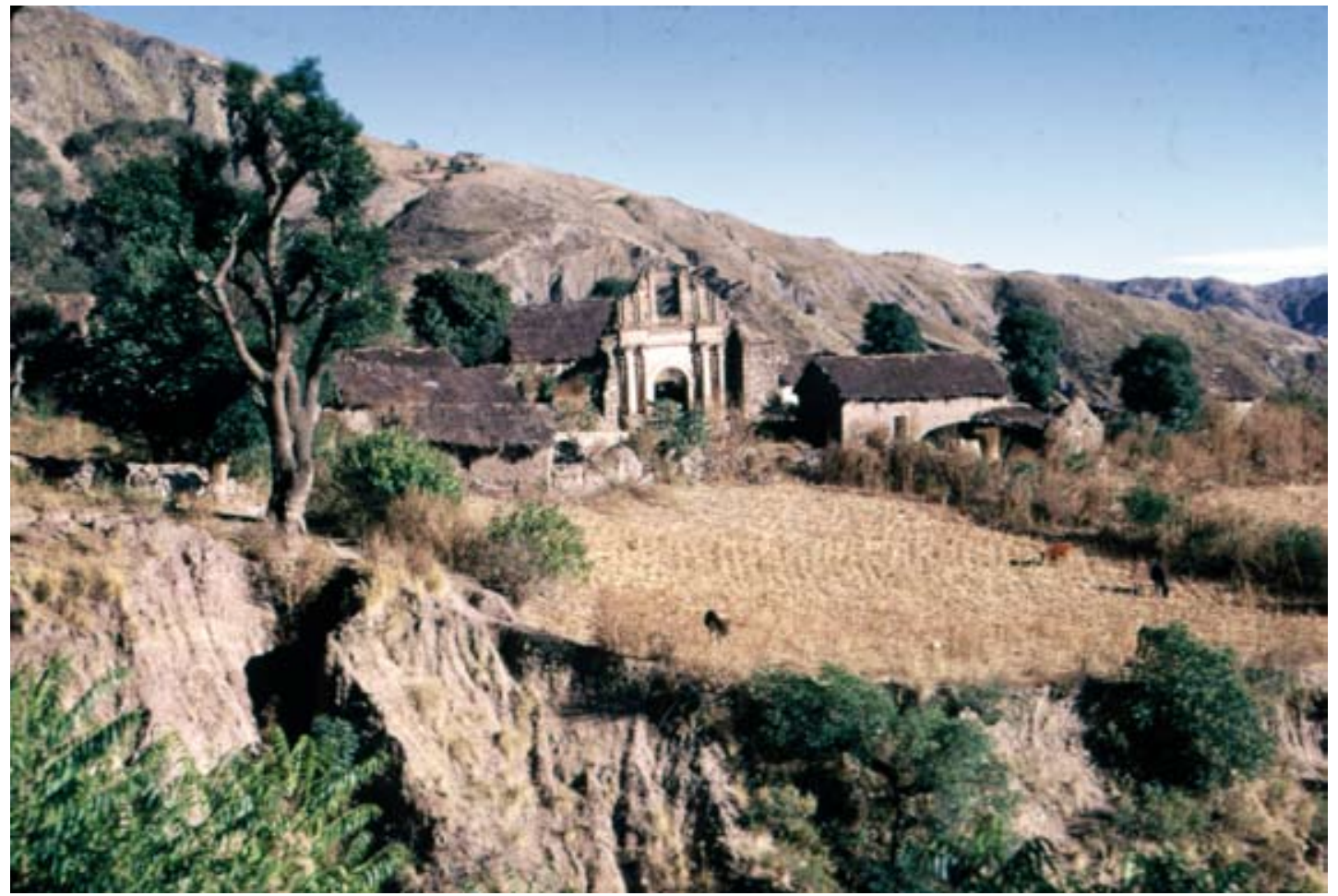

Figura 3. Iglesia de San Marcos de Miraflores (1971).

Church of San Marcos de Miraflores (1971).

Así, podemos encontrar huellas de una relación ceremonial formalizada entre la puna y el valle, así como un "rito de pasaje" entre ambos ${ }^{12}$.

Desde el punto de vista del valle, los vínculos con sus parientes en la puna son mirados con bastante ambivalencia. Hay quienes afirman que "espíritus ladrones de las montañas" (suwa jurq'u) pueden llegar de la puna y comerse el maíz durante una granizada, salvo si se los espanta con estallidos de dinamita. En sus visitas estacionales, los llameros suelen traer consigo bienes de intercambio: sal, arcilla y cerámicas; además de minerales, hierbas del altiplano y hojas de coca (un producto de tierra baja llevado a los mercados altiplánicos). Sin embargo, está en debate si los campesinos maiceros del valle son los socios complementarios de intercambio de los llameros, o si, por lo contrario, son éstos quienes explotan a los residentes de los valles llevándose su maíz ${ }^{13}$. Luego del tinku más grande en la puna, que se celebra en San Pedro de Macha para la fiesta de la Vera Cruz (wilakrus, el 3 de mayo), los llameros emprenden viaje hacia los lejanos valles donde, para la fiesta de Corpus Christi, se realiza el más importante tinku valluno en el viejo pueblo colonial de San Marcos de Miraflores. Ahí se da la participación de miembros de los ayllus tanto de la puna como del valle ${ }^{14}$. Los llameros pueden ausentarse hasta tres o cuatro meses antes de retornar con sus llamas cargadas del maíz que les servirá para mantenerse durante el período de siembra y crecimiento de las plantas en la puna, hasta cuando hacia febrero o marzo llegan las primeras cosechas de papas tempranas. Es tarea de las mujeres velar de la dispensa y asegurarse de que el abastecimiento de maíz almacenado en costales y en los graneros (pirqa) "alcance" (muchuy, o awantay, del español "aguantar") hasta cuando estén disponibles los productos de puna del año siguiente.

La tierra es un recurso frágil en los Andes, exige trabajo incesante, tanto para su preparación como para su cultivo, su administración y defensa, y para su nutrición y propiciación ceremoniales. Aun la guerra se la conceptúa a veces en términos extraídos de la organización del trabajo (p.ej., el término chuqhunaku, para decir que mucha gente se lanza sobre una víctima aislada, deriva de chuqhu que denota el esfuerzo colectivo de trabajo que converge en un solo beneficiario, junto con el sufijo 
interactivo naku del quechua). Las actividades locales se combinan con negociaciones a los niveles más altos de la organización y, por último, con los representantes locales y regionales de un Estado que, durante los siglos XIX y XX, tuvo pretensiones de privatizar la tierra y acallar los reclamos colectivos. Pero todavía se conserva la parafernalia de un antiguo compromiso de reciprocidad: me refiero al intercambio de servicios y tributo a cambio de protección y de tierra, vínculo que fue desarrollado entre los señores aymara y los vasallos tributarios desde tiempos del Inca y del Rey en el siglo XVI (Platt 1982a, 1991 [1984], 1996; Platt et al. 2006). Es dable inferir que esas expresiones marginales de las relaciones Estado-comunidad (pago de tributo, mantenimiento de postillones, servicios en trabajo, etc.) son rasgos en la actualidad de un Estado diferente y anterior del que intentó, en el período republicano, la privatización de la tierra, la constitución de un mercado de tierras y la implantación de una nueva contribución territorial mediante el levantamiento de catastros. Se podría también argumentar que las prestaciones que se entregaban a lo que he calificado de "Estado Inca-Hapsburgo" siguen todavía vigentes, en forma modificada, en los bordes colectivos del Estado liberal pos-Ilustración.

En otro trabajo he explicado cómo los miembros del ayllu Macha me interpretaron los principios segmentarios que subyacen en la formación de sus alianzas militares (Platt 1978, 1996). Empero, las discrepancias brotan cuando, una vez en el terreno, se coteja ese relato ideal con las pautas de residencia y las afiliaciones sociales efectivas. Porciones del modelo segmentario pueden ser desgranadas por los campesinos de Macha para explicar las razones por las cuales diferentes grupos se alían y enfrentan; pero, en cambio, si se examinan los contextos específicos de alianzas y oposiciones, se dibuja un cuadro mucho más confuso y complejo. En ninguna parte ese cuadro rejunta tanta confusión como la que se da en el "archipiélago" del valle de San Marcos de Miraflores (Figura 1).

Hoy en día, como en el siglo XVI, la sociedad Macha está dividida en cuatro niveles segmentarios básicos; el término "ayllu" se puede utilizar para cada nivel: así, se encontrarán ayllus dentro de otros ayllus y estos, a su vez, dentro de otros ayllus. Lo interno y lo externo son estatutos de carácter relativo: los enemigos a un nivel de la jerarquía pueden, en otro nivel, ser aliados. El nivel máximo del ayllu Macha está dividido en dos mitades distinguidas por asociaciones de género (Anansaya, o Alasaya: "arriba masculino"; Urinsaya, o Majasaya: "abajo femenino"); en diez "ayllus niños" (churi ayllu), cinco de cada una de las dos mitades; y en una cantidad variable de cabildos o ayllus mínimos ${ }^{15}$. La mayoría de los cabildos poseen tierras tanto en la puna como en el valle ${ }^{16}$. Es obvio que si se tiene en cuenta esta jerarquía de identidades anidadas, una pregunta sobre la identidad, la residencia y la pertenencia de una persona a un ayllu puede recibir una variedad de respuestas.

Las estancias patrilocales, o las casas aisladas, de los campesinos indígenas se hallan esparcidas en el territorio de cada cabildo. En el sector de la puna de cada cabildo el grupo territorial está compuesto de varias estancias conocidas por sus topónimos y sus tierras. Cada estancia incluye a los descendientes de uno a más ancestros, a los que se les habían asignado tierras en posesión (tasa) durante la última Revisita apoyada por el gobierno en las últimas décadas del siglo XIX ${ }^{17}$. La posesión de una tasa atribuye derechos a compartir las tierras comunales más altas $\left(\right.$ mantas $\left.^{18}\right)$ que se cultivan en un ciclo de rotación que dura 3-4 años, y después son abandonadas en barbecho durante largos períodos. Lo que fomenta la constitución de estancias nucleadas, tal como que se constata en la puna, es la necesidad que tienen los poseedores de esas tierras de coordinar los ciclos de rotación y llegar a un acuerdo sobre el momento de abrir un nuevo conjunto de barbechos. En efecto, las mantas se encuentran sobre todo en la puna (patarana, chirirana: región alta y fría) y la puja por escoger un conjunto de barbechos bien descansados ofrece un pretexto bastante común para las guerras entre los ayllus (ch'ajwas) (Platt 1982b).

Por otra parte, en las tierras calientes (urarana, q'uñirana: región baja y cálida) cada campesino reside en una casa aislada, rodeada de sus campos de maíz. En estas tierras la tasa de una familia puede consistir en varios lotes dispersos en un abanico de microclimas locales, desde los niveles altos (patarana), los declives medios de las montañas (chawpikinray) hasta abajo, al lecho de los ríos (mayurana, región del río). A una franja de tierra flanqueada por dos barrancos y extendiéndose de lo alto hacia abajo se la llama chhuru. Algunas familias poseen un chhuru completo que incluye una secuencia de microclimas diferentes. Puede llegar a tener un sobrenombre familiar: Choque chhuru, Mamani chhuru, etc. Las diferencias del 
modelo de asentamiento en la puna y el valle reflejan diferencias en cuanto al sistema agrícola de cada "zona de producción" (Mayer 2004 [1985] y, por lo demás, es obvio que el modelo del valle es más compatible que el de la puna con respecto al surgimiento de "islas" individuales.

¿Cómo se vincula la segmentación del ayllu a las alianzas efectivas y las oposiciones negociadas por los campesinos macha? Una querella entre dos grupos que se encuentran al mismo nivel segmentario, pero cada uno perteneciendo a grupos mayores diferentes, debería (según me explicaron) producir una fusión de todos esos grupos de cada lado que comparten la membresía del mismo grupo superior (Platt 1978). Esto significaría que sería de esperar que quienes no estén directamente implicados en la pelea local acudan en apoyo de los que están en la misma categoría estructural, a cambio de auxilio recíproco en sus propios conflictos. Sin embargo, hoy (y quizás antes también) esta pauta no siempre es obedecida, en parte debido a la creciente localización dentro del sistema administrativo del Estado $^{19}$; y en parte también porque, aunque el "imperativo segmentario" es constitutivo de una teoría macha de su propia organización social, no da cuenta de todas las ambigüedades que conllevan las situaciones en la vida real.

Por último, aunque la evidencia documental revela que las mitades y ayllus menores de Macha han permanecido sin cambios desde el siglo XVI en cuanto a nombre y número, los cabildos en cambio parecen dotados de una mayor flexibilidad. A veces, obedeciendo a la demografía local y las presiones políticas, se parten y se reagrupan, aparecen y desaparecen. En verdad, una mayor flexibilidad institucional a este nivel puede, en los pisos ecológicos más altos, permitir un mayor grado de estabilidad de los ayllus menores. Como segmentos territoriales de los ayllus menores, hay indicaciones que los cabildos adquirieron su actual forma en los márgenes rurales de los pueblos de indios durante los primeros años de la República (Platt 2009).

\section{Solidaridad Vecinal y Desplazamientos de Afiliación}

Frente a las presiones de los vecinos dominantes en los valles que tienen otras afiliaciones verticales, las unidades domésticas aisladas en las fronteras internas de la organización macha deben esforzarse para mantener su acceso a sus tierras. Estas "islas" solitarias representan un caso límite, y su situación difiere significativamente de sus contrapartes, los ayllus menores y mínimos (los churi ayllu, o ayllus "niños", y los cabildos) en la puna. Efectivamente, muchas veces deben suspender la afiliación a su mitad, o saya, cuando entra en conflicto con la afiliación de sus vecinos dominantes, haciendo una concesión a la necesidad de lograr una solidaridad vecinal. Entonces, en el valle, la mitad y el ayllu de los ocupantes de una isla pueden ser atenuados, invertidos o "intercambiados" para resguardar su acceso a un lote de tierra aislado. Veamos este proceso en más detalle.

La formación del "archipiélago" de Murra puede ser fácilmente reconocida en la Figura 1 que muestra la afiliación vertical de las "islas", tal como lo pude identificar en los valles de Macha. Conviene introducir una breve explicación antes de observar las relaciones sociales que implica. Cuando vivía en los valles de Macha, al principio no tenía ni la menor idea de la escala de organización en la que los campesinos del lugar estaban involucrados. No existían estudios etnológicos previos de ninguna región del Norte de Potosí y fue solamente luego de casi tres meses que las relaciones de mis vecinos con la lejana puna se me fueron evidenciando. Un día, tres meses luego de mi llegada a San Marcos, me contaron cómo los de Macha y dos otros ayllus máximos, los de Pocoata y Laymi, habían iniciado su descenso desde la puna, alcanzando Carasi que es un cantón ubicado más abajo sobre el río Grande, o Jatun Mayu ${ }^{20}$. Allí esos tres ayllus máximos hasta hoy poseen otras "islas" territoriales. Pero fue en Carasi donde las alpargatas (ujut'as) de los Laymi se rompieron, mientras los Pocoatas y los Macha prosiguieron su descenso llegando finalmente a Mizque, que se ubica a una distancia de muchas leguas en el departamento de Cochabamba, y donde todavía se puede ver una piedra mojón que marca la frontera de "los Charcas"21. Prevenido en 1969 por John Murra de la importancia de la organización vertical en los Andes, abrí mis oídos y comencé a preguntarme sobre las implicaciones sociales y simbólicas que podía tener lo que escuchaba.

Sin embargo, los relatos de mis vecinos sobre la "organización vertical" me parecieron al principio confusos e inconsistentes. Hubo personas que me contaron que, en verdad, había doce ayllus ${ }^{22}$, aunque para cuando salí de San Marcos (luego del Corpus Christi en junio de 1971) había recogido los nombres 
de muchos más grupos locales que esos doce. Hubo otras personas que afirmaban que en la puna había un solo kuraka para las dos mitades; lo cual pudo referirse a la antigua costumbre de alternancia del señorío entre los jefes de las dos mitades (ver Platt et al. 2006), o quizás al hecho de que, en los años setenta, no sobrevivía más que el curacazgo Alasaya. Y otras personas, por lo demás, utilizaban los topónimos para nombrar grupos sociales, quedando los niveles de diferencia difuminados en cuanto a su relación al modelo segmentario. Por cierto, no fue antes de ir a la puna que pude comprender la distinción entre un ayllu menor (los churi ayllu) y un cabildo (o ayllu mínimo), ya que era pocas veces relevante en la formación de alianzas en el valle.

Por ejemplo, los "Yuqhunas" dominan el área central en torno al propio San Marcos (Figura 1: número 21, ver Apéndice). Se los considera equivalentes a otros grupos como el de los "Amutaras" (7), o a los "Lluchus" y "Chaytas" (2, 3). Fue sólo en la puna que me informaron que los Yuqhunas eran un cabildo menor del ayllu MajaQuyana; que Amutara era, en verdad, el nombre de una ladera frente a San Marcos donde el cabildo Yuraqari (ayllu menor AlaQuyana) tenía sus tierras de valle; y que Chayta y Lluchhu eran anexos parroquiales donde los cabildos Ayuma, Pichichhua y Pumpuri (también de AlaQuyana) poseían entremezcladas sus tierras de valle. Los topónimos y diferentes niveles de organización, por lo general diferenciados en la puna, estaban siendo mezclados en los valles para nombrar los contrastes sociales que eran relevantes para la vida cotidiana en San Marcos.

En otra oportunidad, se me dijo que los Waraqhatas $(11,12)$ combatirían contra los Yuqhunas (21). Fue solamente llegando a la puna que caí en cuenta que, aunque demográficamente equilibrados en los valles y, por consiguiente, estimados participantes equivalentes de combate, los dos grupos en realidad pertenecían a diferentes niveles segmentarios de organización: el nombre de un churi ayllu (Waraqhata) estaba siendo considerado equivalente a un nombre de cabildo (Yuqhuna). Mi perspectiva estaba afectada por el hecho de que vivía en Yuqhuna, en una choza abandonada de adobe destartalada, ubicada a veinte minutos a pie desde el pueblo arruinado. Con lo cual se me presentaba con los contrastes sociales que eran particularmente significativos para mi estatus en tanto residente de Yuqhuna. Y descubrí que la mayoría de los campesinos "saben", por lo general, tan sólo los aspectos de la organización social que directamente les conciernen ${ }^{23}$.

Por consiguiente, la Figura 1 y el Apéndice traen información reunida en el valle, pero glosada a la luz del sistema tributario que me fue explicado posteriormente en la puna. Esto tiene la ventaja de que permite una identificación más precisa de cada grupo social local. Empero, no toda esta información era considerada relevante, ni aun conocida todo el tiempo, por todos los habitantes del valle. Las características locales de la organización eran desplegadas y reproducidas a lo largo de casi todo el año sin necesidad de tener en cuenta el modelo segmentario formal, que era conservado en las listas de los tributarios del kuraka en la puna. En algunos casos, la dispersión de los ayllus menores en el valle había conducido al surgimiento de agrupamientos diferentes que no eran para nada reconocidos en el modelo general de la puna. Los Wakhuatas de Wilakota (35), para dar un ejemplo, eran reconocidos en el valle como jatun wakhuatas ("Wakhuata mayor") en contraste con los Illili y Sikuta $(36,37)$ que se los llamaba churi wakhuatas ("Wakhuata niño"). Nuevamente, los Sullkhawis de Chhari-chhari y Ichurata $(9,8)$ son distinguidos como juch'uy y jatun (mayor y menor), respectivamente. Visto desde la perspectiva de la puna, estas distinciones locales no son percibidas como formando parte de la organización general de la sociedad macha, aun si, como ocurre, diferenciaciones similares también se incluyen en algunas formas locales de autoidentificación en la puna ${ }^{24}$.

No obstante, una diferencia dominante parece ser compartida por ambas regiones: las dos mitades en teoría son endógamas, y se contraponen de varias maneras, especialmente en la violenta hostilidad que florece durante los tinkus y los ch'ajwas. Todos los macha pueden ser clasificados por sí mismos y por los demás ya sea en Alasaya (mitad de arriba) o en Majasaya (mitad de abajo) (Figura 1). Resulta sorprendente, entonces, que, en la sociedad valluna, esta oposición omniabarcadora se difumine y se torne problemática a la luz de las posiciones vulnerables y contradictorias de muchos enclaves "islas".

Miremos los casos en que las "islas" Alasaya están rodeadas por un vecindario Majasaya y viceversa. ¿Cómo se pueden mantener estas situaciones heterárquicas pero desiguales? En primer lugar conviene fijarse en los diferentes niveles de organización segmentaria por los que una isla puede ser diferenciada con respecto a sus vecinos: 
1. Una isla de una mitad puede estar anidada dentro de otra mitad; p.ej. Sullkhata (Majasaya; 33, Figura 1) dentro del territorio extendido de Sulkhawi (Alasaya, 28); o Kuimuri (AlaQuyana, 5) dentro de Yuqhuna (MajaQuyana, 21).

2. Una isla de un ayllu menor puede quedar inserta en otro ayllu menor de la misma mitad; p.ej., los Taphunatas de Carpani (15) dentro de Sullkhawi (28), ambos de Alasaya; o Kunthawata (4) dentro de Yuqhuna (MajaQuyana, 21), ambos de Majasaya.

3. Una isla de un cabildo puede estar situada dentro de otro cabildo del mismo ayllu menor; p.ej. la isla Kunthawata 13 dentro de la isla Kunthawata 31 (su identificación de cabildo es incierta).

4. Un grupo viene de un ayllu máximo diferente: los k'ultas de Llanquiri (1), procedentes del ayllu de K'ulta en la puna, e implantados dentro de los AlaQuyanas de Macha en Chayta y Lluchhu $(2,3)$. Aquí, el contraste entre isla/vecindario se da al nivel de los ayllus máximos que están implicados.

Esto nos da una idea de la complejidad de situaciones encubiertas por la frase "multiétnico", comúnmente utilizada en la literatura etnohistórica sobre los "archipiélagos" y sus "islas". En realidad, las afiliaciones verticales se combinan con varios grados de diferencia social entre distintas "islas" y su entorno de vecinos, y esto llega a niveles muy por debajo del contraste general entre ayllus máximos. La pregunta que se nos presenta ahora es saber cómo pueden reproducirse a lo largo del tiempo estas sutiles gradaciones entre islas y vecinos en distintos niveles segmentarios. Aquí será provechoso distinguir entre las relaciones sociales referentes al vecindario local y las que expresan la afiliación vertical de cada unidad doméstica a su grupo de parentesco, cabildo, ayllu y mitad en la puna ${ }^{25}$. Pues, contrariamente a Thierry Saignes $(1978,1985)$ y a pesar de las sugerencias sobre este punto hechas por Bernabé Cobo (Historia del Nuevo Mundo 1964 [1660], Lib. XI, Cap. 23), no encuentro que sean recíprocamente excluyentes la solidaridad local y la afiliación vertical al ayllu, ni que se inserten necesariamente en una secuencia temporal lineal.
Permítaseme presentar aquí cuatro contextos donde la afiliación vertical de cada unidad doméstica del valle tiene una clara precedencia sobre su pertenencia al vecindario local.

1. El pago de tributo. Las ceremonias de pago (también conocidas como cabildos) se verifican también en el valle, donde concurren los dispersos representantes de cada cabildo territorial y ayllu menor dentro de San Marcos. Es normal que los cabildos del semestre de San Juan se efectúen en los valles, dado que mucha gente de la puna se halla también en los valles para ese período ( 21 de junio), trajinando en intercambios entre la sal, el chuño y otros productos de altura a cambio del maíz que precisan para sobrevivir en la puna antes que se cosechen las primeras papas. Cada cabildo está apadrinado por un cobrador nombrado anualmente, que debe aportar la chicha, coca y el alcohol requeridos en la ceremonia. Como ya se ha visto anteriormente, la ceremonia de pago del tributo facilita que se congreguen los miembros dispersos de cada grupo social, ya sea que residan normalmente en la puna, o que vivan esparcidos entre diversos enclaves en el "revoltijo" valluno ${ }^{26}$.

2. Intercambio vertical. Cada año, entre abril y septiembre, las hileras de llamas descienden de la puna, atraviesan montañas y gargantas, siguen el lecho de los ríos y bajan por las quebradas. Cruzan pasos entre picos de montañas que caen hasta llegar a los valles calientes, productores de maíz, donde se involucran en relaciones de intercambio o de comercio con sus parientes, compañeros de ayllu u otros participantes. Es ésta la clásica racionalidad de las afiliaciones verticales que ha sido tan bien descrita, para Macha, por Cassandra Torrico (s/f). Torrico ha explicado cómo las listas de los costales utilizados por los llameros simbolizan los principales productos que corresponden a cada zona, propiciando transacciones exitosas y la adquisición de suficientes alimentos (sobre todo maíz) para poder aguantar hasta el año siguiente.

3. Corpus Christi. En mayo o junio todos los concurrentes de la puna se congregan 
en San Marcos con sus camaradas de los valles para participar en la gran fiesta móvil de Corpus Christi (en el caso de los K'ultas de Llanquiri, el 29 de junio, para la fiesta patronal fija de San Pedro). Las cosechas de maíz se celebran allí con una misa dedicada a la hostia (el cuerpo solar de Cristo) y se hacen ofrendas propiciatorias para un exitoso año siguiente. También se realiza un gran tinku en el que se espera que todos los concurrentes de la puna y los residentes locales se coliguen obedeciendo a sus afiliaciones de ayllu y de vecindad (Platt 1996).

4. Servicios y obligaciones verticales. Afianzar la tenencia de la tierra también exige el cumplimiento de algunos servicios en trabajo para el Estado a nombre de la mitad, del ayllu menor y del cabildo de cada cual. De los servicios, durante la colonia, el más importante fue la mit' $a$ en las minas de Potosí (Platt 1983; Saignes 1985; Tandeter 1992). También se esperaba que las unidades domésticas que gozaban del acceso a tierras en ambas zonas ecológicas participaran en el apadrinamiento de las fiestas religiosas en cada zona, y sirvieran de cobradores del tributo, de alcaldes y de postillones. Hasta 1972 se conservó un servicio de correo en el tambo del pueblo de Macha en la puna; además, en ese tambo los viajeros podían proveerse de comida y alojarse, y cada mitad disponía de su propia huerta. Los propietarios de tierras en la puna y en el valle eran nombrados por turnos para cumplir esta tarea ${ }^{27}$. Se esperaban obligaciones semejantes de los K'ulta de Llanquiri que, en 1971, todavía continuaban cumpliendo con el servicio de postillones en el pueblo de Santa Bárbara de Culta, situado en el Altiplano del departamento de Oruro ${ }^{28}$.

Aunque este listado no pretende ser exhaustivo, sin embargo sí ilustra un abanico de contextos en los que la afiliación vertical es dominante. Empero, a lo largo de una buena parte del año las preocupaciones de vecindario predominan sobre los asuntos verticales y las islas con una afiliación vertical diferente de la del "anfitrión" que las acoge deben encontrar un modus vivendi para lograr su supervivencia. Para observar cómo se logra esto, detengámonos en algunos casos particulares:

1. La isla 4 es una isla aislada del churi ayllu Sullkahata (cabildo Juluch'i) muy consciente de su posición conflictiva pues rodeada de Yuqhunas (ayllu MajaQuayana, 21), aun sí ambos ayllus menores pertenecen a la misma mitad Majasaya. Es de aquí aquel hombre que me decía que era $p$ 'itijta-sqa (significando $p$ 'itiy "romperse" una hebra: /jta/ es un afijo aymara que expresa la idea de una "separación repentina", y /sqa/ marca aquí el participio pasado). Esta imagen pertenece al vocabulario del hilado y tejido: extiende la metáfora de la organización geográfica que Harris extrajo del trabajo de Cereceda sobre los diseños textiles. Los habitantes de las islas se representan a sí mismos como "hilos rotos" en el tejido supuestamente suave del vecindario. Lo cual acarrea implicaciones a la hora de escoger a sus aliados e identificar a sus enemigos. Es así que pasó la fiesta del 3 de mayo para el "Padre Vera Cruz", o Tata Wilakrus ${ }^{29}$, a veces con los Yuqhunas, y otras veces con los vecinos Sullkahawis (9, Charichari) que son de la mitad opuesta Alasaya.

Tata Wilakrus es el nombre que se da a unas cruces de madera de grandes proporciones, pintadas de símbolos de la fertilidad, que se hospeda en los calvarios (capillas pequeñas) ubicados en las cumbres de pequeños cerros en cada vecindario. El Tata es el compañero de las vírgenes (wirjinas) que residen en los campos del entorno. Cuando la fiesta se las viste con un poncho y un casco de guerra, una talega de coca y un cinturón tejido (chumpi). Luego, cada cruz es cargada desde la estancia de turno a la iglesia de la parroquia en el hombro de un combatiente, en medio del grupo de guerreros locales con casco, mientras las julajulas entonan algo parecido a un canto gregoriano que se ajusta al ritmo estricto de un largo paso de marcha militar. Una vez allí, el Tata Wilakrus oirá misa y presidirá el ritual de combate (tinku) al final de la fiesta (Platt 1996; $c f$. Stobart 2006 sobre la música y los bailes de guerra). 
Al unirse en ciertas ocasiones a los enemigos de los Yuqhunas, este hombre aislado de Sullkhata revela su propia inseguridad, a la vez que su deseo de buscar apoyos de ambas mitades cuyas parcelas se hallan cercanas a las suyas propias, y cuyas Cruces pueden, ambas, proveer fertilidad y protección para sus tierras.

2. En el Carnaval, las dos mitades Alasaya y Majasaya forman dos grupos ceremoniales diferentes y contrapuestos, con la excepción de las islas que, una vez más, se asocian al grupo que domina su vecindario para celebrar una fiesta local que marca la transición de la estación húmeda de crecimiento de las plantas a la seca de maduración y cosechas ${ }^{30}$.

3. La isla 5 pertenece al cabildo Kuimuri de AlaQuayana (Alasaya). Su ocupante cayó en cuenta que vivir rodeados de Majasayas (cabildo Yuqhuna, ayllu menor MajaQuyana, 21) acarreaba una tal tensión que decidió dejar sus tierras a un inquilino de Majasaya (ayllu minor Wakhuata de Wilakuta, 35) que, pensaba, pudiera mantener relaciones más sueltas con el grupo local dominante.

4. Sin embargo el nuevo inquilino Majasaya se sintió obligado a participar en la comparsa Alasaya en el tinku, ya que era la mitad que recaudaba el tributo correspondiente a su nueva parcela. Un cambio de ayllu implica por lo general combatir al lado del nuevo grupo. El nuevo inquilino (tenant) trataba de cambiar su adhesión y asumir las nuevas obligaciones hacia la mitad Alasaya a fin de consolidar la posesión de su tierra. En eso estaba cuando los vecinos Yuqhunas le propinaron una paliza. Entonces, el inquilino cambió de opinión y declaró que se hallaba del lado de los Yuqhunas (mitad Majasaya), aun si el propietario de la parcela seguía pagando el tributo al cabildo de Kuymuri (Alasaya). El inquilino comenzó a combatir del lado de los Majasayas y hasta le echó una filípica al habitante de la isla 6 (de ferviente lealdad AlaQuyana, de Alasaya) sobre la importancia de la solidaridad local con los Majasayas. Su nueva actitud coincidió, claro está, con sus propios orígenes Majasaya; sin embargo, resulta significativo que durante el Corpus Christi de 1971 participó en la fiesta del alférez de AlaQuyana (de Alasaya) y, por ende, obtuvo comida y bebida de los "dueños" de la tierra que abonaban el tributo.

5. De similar manera, los K'ultas de Llanquiri (isla 1) combatieron al lado de los AlaQuyanas (Alasaya) que son preponderantes en el vecindario donde se encuentran situadas sus tierras. Pudieron así conservar su afiliación vertical, aunque estaban temerosos de sus vecinos macha. Algunos hasta comenzaron a "convertirse en macha", trasladando los pagos del tributo y sus obligaciones (como p.ej., los servicios postales) de Culta a Macha. De continuar así esto, hubiera podido acarrear un cambio de ayllu y los k'ultas probablemente se habrían adherido a su entorno de AlaQuayanas. Sin embargo, hubo algunos que continuaron impertérritos: decían que sus tierras seguirían siendo de K'ulta hasta que los de Macha devolvieran el quintal de oro (quri kintal) que, supuestamente, los llameros de K'ulta les prestaron para que abonaran el tributo, a cambio del terreno de Llanquiri ${ }^{31}$.

6. Un caso particularmente significativo es el de una pareja de AlaQuyana (7), padres de una hija y tres hijos que, careciendo de suficientes tierras en su cabildo original (identificación Yuraqhari en la puna, localidad valluna Amutara), pidió permiso para cultivar un lote baldío en el territorio de los Sullkhawis de Ichurata (8). Eran todos miembros de la mitad Alasaya. El permiso le fue otorgado a la pareja a condición de que sus hijos asistieran a la escuela en Ichurata (construida por los Sullkhawis), ayudaran a mantener los senderos en el sector y que, como es costumbre, combatieran del lado de los Sullkhawis durante los tinkus y los ch'ajwas.

El acuerdo se prolongó durante dos años, hasta cuando el marido y el hijo mayor murieron. Imposibilitados de cultivar las tierras por sí solos, la viuda y los demás hijos retornaron a AlaQuyana, a vivir en las tierras que habían pertenecido al marido muerto. Lo que les fue permitido porque todavía quedaban dos hijos que eran los herederos de las tierras de su padre; de lo 
contrario, los hermanos del marido muerto habrían tenido un derecho preeminente sobre esas tierras y la viuda hubiera debido retornar donde sus padres y a su parentela de nacimiento. Ahora, ocurre que poco luego la viuda contrajo nuevas nupcias con otro AlaQuyana que, esta vez, era de la puna; e intentaron retornar al lote en Sullkhawi ya que su nuevo marido no estaba dispuesto a mantener los hijastros en tierras donde él y sus propios hijos hubieran sido excluidos.

Mientras tanto, los Sullkhawis, al ver que la viuda había abandonado el lote, lo habían reasignado a uno de sus miembros desprovisto de tierra. Despojaron a la viuda en una ceremonia: el ayllu hizo un ch'aki chuqhu, un grupo de trabajo "sin chicha", en el que cada hombre, incluyendo al potencial pretendiente, aró y sembró un par de surcos. Al año siguiente, la cosecha fue compartida entre todo el ayllu y la posesión entregada al nuevo ocupante ${ }^{32}$.

Dos aspectos se pueden extraer de este caso. El primero es que la ceremonia de despojo expresa a la vez, tanto los derechos de reversión que el ayllu menor (y, más allá, la mitad y el ayllu máximo de Macha) puede sustentar sobre las tierras dentro de su dominio colectivo, como, simultáneamente, las dificultades que enfrenta ese derecho al ser reclamado, puesto que el lote tuvo que ser arado colectivamente, sembrado, cosechado y su producto distribuido antes de que el ayllu pudiera disponer nuevamente del terreno. El segundo es que la entrada de la pareja AlaQuyana en el lote fue interpretada por su ayllu de origen como -al menos potencialmente- una expansión de su propio dominio. Lo cual se revela en el hecho de que los AlaQuyanas y los Sullkhawis llegaron a pelearse a golpes sobre este asunto en San Marcos durante la fiesta de Corpus Christi en 1968.

Lamentablemente el asunto clave, en cuanto a la membresía del cabildo, queda sin respuesta puesto que los AlaQuyanas no estaban pagando el tributo en ese momento debido a la Segunda Reforma Agraria $^{33}$. Si la pareja AlaQuyana hubiera permanecido en Sullkhawi y cumplido con sus obligaciones de vecindario, como lo exigían sus "huéspedes", si hubieran seguido pagando su tributo junto con los demás de su cabildo (Yuraqari), entonces se habrían reunido todas las condiciones para que emerja una nueva isla. Asimismo, este caso revela cómo las circunstancias podrían conducir a la desaparición de una isla, si hay un desplazamiento de las exigencias sociales de ambos lados.

En lugar de ratificar la situación inamovible de las islas de larga duración, entonces, algunas pueden, en cambio, ser vistas más bien como la fluida expresión de un proceso dinámico: "burbujas" efímeras que se inflan y estallan, empleando una metáfora alternativa ( $c f$. Saignes 1978). Se puede arriesgar una inferencia: aún si no existiese un aparato de Estado dispuesto a garantizar la seguridad de la tenencia y del acceso a la tierra, podrían darse circunstancias que llevarían a que pequeños grupos de lejanos colonos del altiplano, aun siendo familias solas, fueran abiertamente acogidas en el seno de un grupo diferente que ya está asentado en las tierras bajas y que necesita aliados para aguantar las presiones de los vecinos. Los nuevos colonos podrían ser aceptados si pagaban el precio de su apoyo militar; pero podrían ser expulsados si su presencia ya no convenía a sus anfitriones, a menos de que puedan gozar del apoyo efectivo de su propio ayllu u otros aliados.

Los ejemplos aquí dados han aclarado, creemos, un tema fundamental: la supervivencia de las islas está condicionada a su voluntad de pelear a nombre de los anfitriones que las rodean aun cuando eso pueda significar tener que combatir contra su propia mitad. A lo largo de casi todo el año están inmersas en una red de obligaciones de vecindario que adquiere precedencia frente a otros lazos. Ocurre como si reinara un consenso en que esas aisladas "hebras rotas" hay que reatarlas de alguna manera al tejido homogéneo de los grupos y de las territorialidades locales, mientras que los anfitriones echan la vista gorda en las pocas ocasiones cuando las afiliaciones verticales vuelven a brotar.

Aun si se introducen estos condicionantes, de todas maneras la situación de las islas está por lo 
general cargada de fárrago: según sus circunstancias, cada una responde al aislamiento a su propia manera. Se ha visto el caso de aquel Alasaya que, rodeado de Majasayas, se vio obligado a entregar la tierra a otro de Majasaya, el que, a su vez, se vio obligado a contrabalancear sus solidaridades entre los Majasayas, que dominaban localmente, y los Alasayas, a los cuales la parcela aún pertenecía. También está el caso de una isla Majasaya, atrapada entre diferentes ayllus de ambas mitades, que simplemente escogió alternar los servicios y las solidaridades entre Majasayas y Alasayas. Por otra parte, un pedido de tierras que surja desde dentro de un grupo anfitrión puede llegar a bloquear la formación o la persistencia de una isla, incluso en algunos casos llegando a la expropiación y expulsión.

Está claro que la inestabilidad de las islas puede llegar a provocar tensiones entre ayllus y mitades que, a su vez, pueden desembocar en situaciones de violencia (tinku). Cabe introducir, sin embargo, un rasgo significativo en cuanto a las alianzas de vecindad que muestra que, aunque la membresía de una mitad puede quedar suspendida en vista de los intereses de la solidaridad de vecindario, hay límites impuestos al alcance de la violencia redirigida hacia la propia mitad. Un combatiente de Majasaya no puede golpear sin más ni más a cualquier Majasaya sin hacer excepciones, pues puede terminar por golpear a sus compañeros de ayllu y parientes. Personas pertenecientes a ambas mitades me aseguraban que ninguna isla debía pegar a alguien del mismo ayllu menor (churi ayllu) que el suyo propio. Si se viera compelida a pelear contra su propia mitad por sus vecinos que la engullen, puede combatir solamente con los compañeros más distantes de esa mitad, pero de ninguna manera enfrentarse a los que son miembros del mismo ayllu menor.

Lo cual indica la manera como se imponen límites a los efectos de desintegración social que podría provocar la "traición obligada" de una isla, al tratarse de su propia mitad. El ayllu menor de afiliación vertical permanece por sí mismo solidario e intacto; en cambio, los otros cuatro ayllus de la misma mitad se convierten en los enemigos de una isla compelida a colaborar con sus vecinos de la mitad opuesta. ¿Quiénes son los mayores enemigos de la isla en este contexto? Es obvio: son los otros cuatro ayllus de su propia mitad; en cambio, sus aliados más poderosos son sus vecinos dominantes de la mitad opuesta. En este escenario patas arriba se mantienen las relaciones entre la isla y su propio ayllu menor: no deben pegarse mutuamente, pero su unidad está sometida a tensión por esos "otros" que proporcionan a la isla un paraguas de protección local.

\section{Discusión}

Por lo general las diferencias sociales entre las mitades endógamas del Norte de Potosí son expresadas en la literatura antropológica en términos de una alianza y oposición estructurales. En última instancia, se puede decir que a quién uno combate, define también a quién uno podría comérselo (o podría ser comido por él); puesto que, en efecto, la comida se comparte con aliados y amigos. Lo cual entrega un criterio fundamental para la identificación social. Sin embargo, entre las "islas" vallunas la situación se revela más flexible y se encauza a lo largo de un continuum de gradaciones sucesivas. Los contrastes polarizados se despliegan entre $n i$ veles segmentarios, siguiendo las tensiones entre lejanas afiliaciones tributarias y las de vecindad ${ }^{34}$. Las alianzas entre mitades pueden invertirse a cambio de obtener seguridad de la tenencia de la tierra en el contexto interdigitado del "archipiélago" del valle, de las "burbujas" del mar o -en palabras más andinas- de "un tejido con hebras rotas". La disolubilidad de la mitad en el contexto local es, de esta manera, equilibrada por la solidaridad del ayllu menor vertical.

A su vez, las islas del valle se ven constreñidas a contar con la protección de su otra mitad que domina en su vecindario, mientras que, al mismo tiempo, transforman en enemistad su usual alianza con los cuatro otros ayllus que constituyen el resto de su mitad. Queda claro, por consiguiente, que la oposición entre mitades no ejerce un supuesto papel de algún "imperativo estructural" en la formación de las alianzas. Más bien, bajo las presiones políticoeconómicas y coercitivas locales, ese imperativo puede ser fracturado y transferido. En este contexto, tan sólo el ayllu menor permanece como el ápex moral y de solidaridad de la organización vertical.

Soy de la opinión que estamos en presencia de huellas de una pauta de negociación de larga duración, que se reverbera con aquellos compromisos realizados por los ayllus menores en la puna cuando recién comenzaron, en el "período de guerra" del Intermedio Tardío (o, aún, quizás, desde mucho antes), a bajar del altiplano y entremezclarse en 
valles adyacentes, a veces instalando algunas islas que perduran hasta hoy en día. Los acuerdos políticos parecen ser inherentes a la práctica del cultivo vertical en los valles por diversos grupos de ayllus menores de la puna. La interdigitación de islas de diferentes grupos étnicos puede ser considerada como una manera completamente aceptable de reclutar a nuevos miembros que ayuden a defender un vecindario débil. La situación actual podría, aún más, reflejar el proceso por el cual cada mitad se constituyó originalmente en la puna a partir de una micro-federación de churi ayllus.

A su vez, cada ayllu menor, o churi ayllu, estaba compuesto de lo que el Inca llamaba "cientos" o ayllus mínimos, cada uno con sus mallki ancestrales, sus lugares sagrados de origen (huacas y paqarina) y sus "estolones" verticales. La intervención del Inca tal vez pueda reflejarse en la institución de, precisamente, cinco ayllus churi en cada mitad; empero, las mitades en sí mismas son casi con toda seguridad preincaicas aún si, hoy en día, se las atribuye al surgimiento del Inca-Cristo-Sol (Platt et al. 2006; Platt 1996). La información de que hoy en día disponemos nos sugiere que los ayllus menores (y mínimos) en la puna, que están compuestos de varios patrilinajes que se casan entre sí y descienden de un hombre o de una pareja masculina-femenina ápice, (los troncos de casas, como se los llamaba en el siglo XVI hispánico, ver Platt et al. 2006, Parte V), probablemente fueron los componentes básicos con cuyas alianzas se armó la sociedad de Macha $^{35}$.

Cada ayllu menor o mínimo puede haber sido, entonces, un grupo de tendencia endogámica, compuesto de unidades más pequeñas de linajes que se casaban entre sí, cada uno de los cuales derivaba de sus respectivas huacas ancestrales de la puna (como las momias chullpa de los fundadores de las casas, o los remotos lugares de origen ubicados en paisajes sacros). Los "cientos" fueron probablemente los antecedentes de los cabildos coloniales y republicanos (otro nombre dado a los ayllus mínimos), constituidos por conjuntos de grupos de descendencia vinculados por matrimonio. En la actualidad dentro de cada cabildo viven grupos de patrilinajes virilocales en torno a su respectiva capilla, calvario, en la que se conserva la Cruz de las batallas (tata wilakrus $=$ el Padre Vera Cruz): es una cruz fálica que algunas veces está pintada con símbolos de fertilidad y, por lo general, exhibe una cabeza de Cristo en el medio ${ }^{36}$. Es dable pensar que la huaca ancestral de los grupos patrilineales dentro de una pachaca fuera reemplazada, bajo el dominio español, por una cruz de calvario. El 3 de mayo, fiesta de la Cruz, estas cruces, guardadas casi todo el año dentro de las pequeñas capillas de los calvarios, son vestidas, como hemos visto, en atuendo de guerra y cargadas por sus congregaciones hasta la iglesia parroquial de Macha. En la iglesia, oyen la misa dedicada a la Hostia del Sol (Platt 1996) antes de salir a la luz del sol para otorgar renovado animu y kallpa (fuerza) a las proezas de sus guerreros devotos en el tinku (Figuras 4 y 5).

Se ha visto que la "mezcla" de los ayllus en los valles en diferentes niveles segmentarios yuxtapone unidades domésticas que en la puna pertenecen a diversos ayllus y cabildos separados espacialmente. Por lo tanto, las presiones hacia la alianza segmentaria pueden también provenir de las tierras bajas hacia la puna, antes que al revés. Por ejemplo, las cosechas de San Marcos son un momento de fusión máxima de todo el ayllu de Macha que se expresa por medio del tinku en el que, de cada lado, los llameros de la puna participan en alianza con los campesinos maiceros del valle. Hemos visto que en el pueblo valluno de Carasi, y a un nivel más alto de la formación segmentaria, Machas y Pocoatas se unen para enfrentarse a Laymis y Puracas, éstos siendo ambos parte de la mitad de arriba (Anansaya) de Chayanta, históricamente parte de la federación Qaraqara que dependía de Macha. Estos niveles altos de alianzas en el valle pueden llegar aún a impulsar alianzas similares en el altiplano, donde los aliados pueden vivir mucho más alejados unos de otros y que, de otro modo, tendrían menos incentivos para entrar en una coalición ${ }^{37}$.

He sugerido que esas negociaciones, reformulaciones y mutuas concesiones entre los ayllus dejan huellas de las negociaciones políticas y religiosas por las cuales se fueron constituyendo históricamente. Las negociaciones pueden llegar a realizarse al margen de un Estado abarcador (over-arching) con capacidad de imponer un "paraguas" de paz, orden y legitimidad sobre sus tributarios ${ }^{38}$. A su vez, esas negociaciones se dan dentro de un ethos guerrero, alimentado por competiciones colectivas (tinkus), y también por enfrentamientos más salvajes (ch'ajwas) en los que conflictos predatorios y de defensa, sacrificios religiosos y canibalismo, se realizan en las fronteras inestables de los grupos. Es el lugar donde los enfrentamientos relativamente ordenados entre toros rivales se disuelven en una 


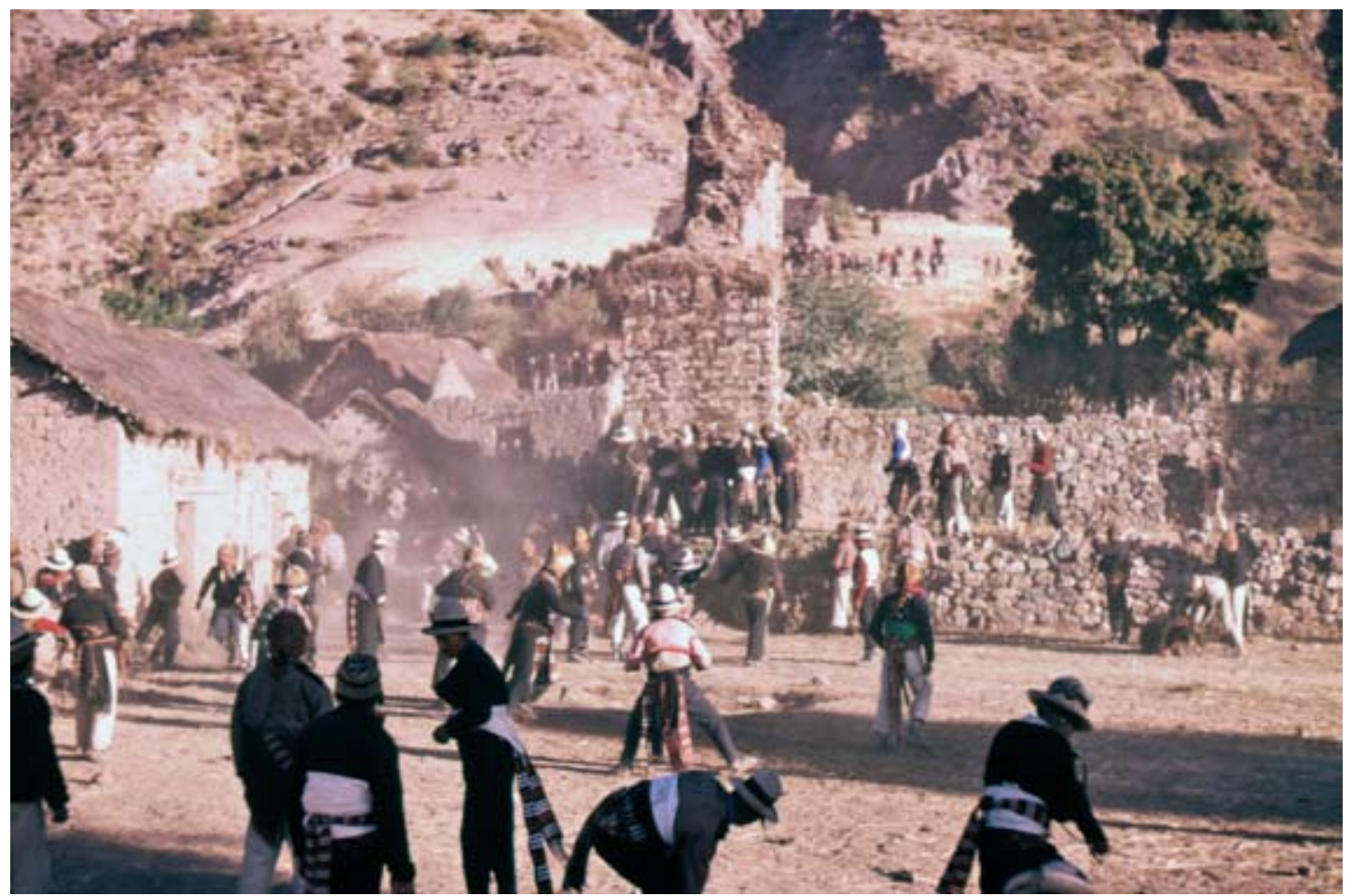

Figura 4. Tinku en San Marcos de Miraflores (Corpus Christi 1971).

The tinku in San Marcos de Miraflores (Corpus Christi, 1971).

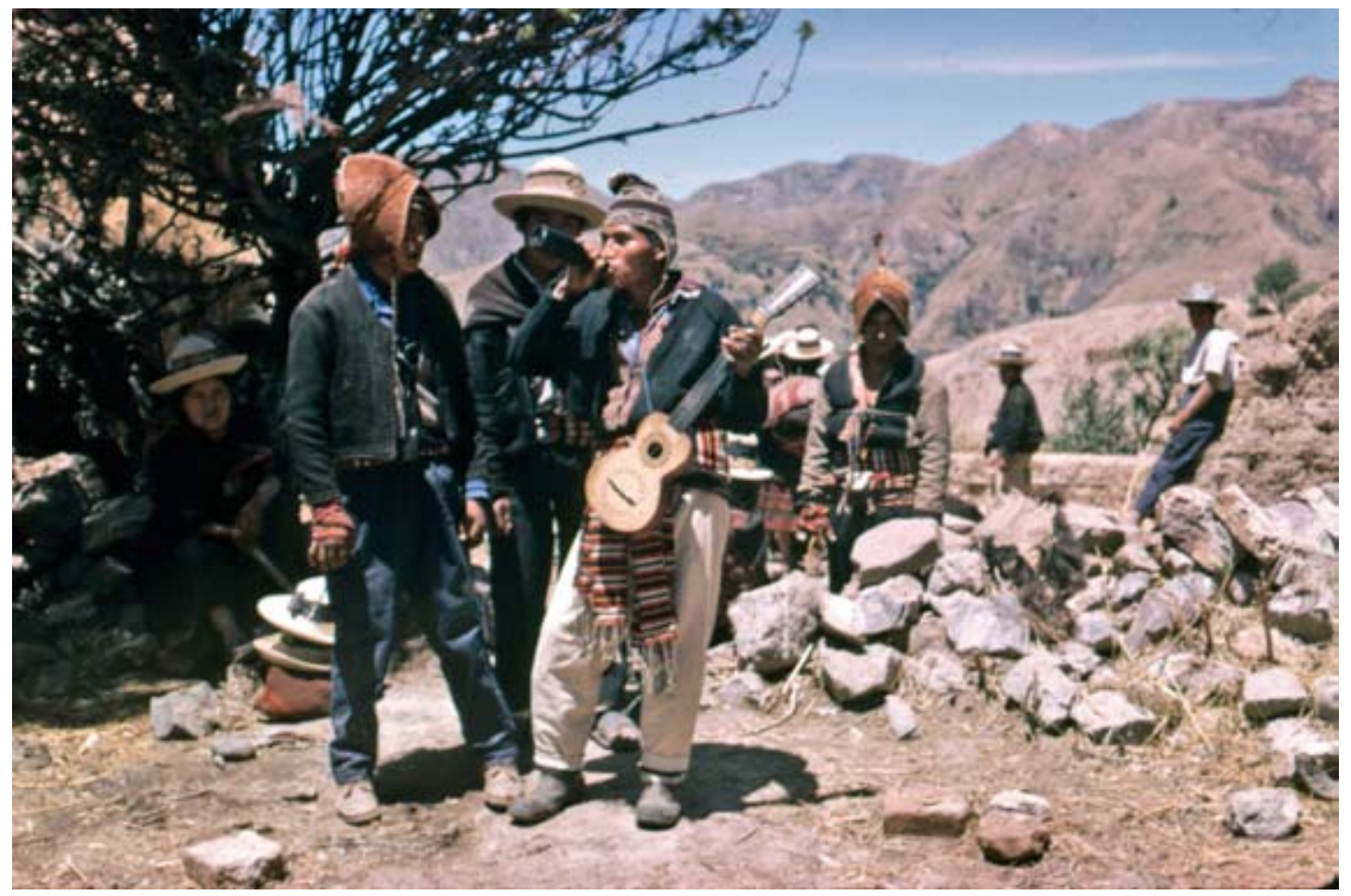

Figura 5. Guerreros descansando (1971).

Warriors at rest (1971). 
desatada liberación de energías de cada combatiente enloquecido que trasmuta su figura en animal silvestre. Sin embargo, hemos visto que también hay posiciones intermediarias entre las polares categorías de compañeros de ayllu (que se expresan idealmente en actos comensales) y de enemigos (que son un objeto potencial de canibalismo).

Estas escalas intermedias son un aspecto esencial del tejido político flexible elaborado por las sociedades de habla aymara (y quizás, antes, puquina) del altiplano, tanto como por los Incas tardíos: un verdadero bosque de estolones que llega desde sus lejanos parientes mallki en la puna para combinarse $\mathrm{y}$ arraigarse en las tierras calientes, a la vez como integrantes de los asentamientos locales y como extensiones de sus respectivos grupos verticales. Probablemente, los ayllus construyeron su sistema segmentario bajo la protección de las divinidades de arriba (janajpacha) y de las de adentro de la tierra (ukupacha), fuerzas que dominaban, sacralizaban y definían las fronteras del mundo social con el sagrado mundo silvestre. Lo cual no ha impedido que la gente pudiese construir y desplazar lealtades y devociones, reestructurando sus federaciones y corriendo los límites territoriales y hasta sus lugares de culto, en concordancia a las nuevas presiones demográficas y políticas. Las afiliaciones sociales hacen a la gente, pero a su vez son constantemente rehechas por ella. La guerra y el conflicto son instrumentos de esa remodelación.

Hemos visto que las guerras modernas de los campesinos evocan situaciones emparentadas con las del pasado, en las que señores de confederaciones lideraban ejércitos de combatientes transformadores que hacían presa a sus rivales y recogían sus cabezas como trofeos para ofrecer inmolaciones a los espíritus ancestrales que moraban en el paisa$\mathrm{je}^{39}$. En la Amazonia moderna, entre la gente del tiempo mítico son bien conocidas las relaciones entre los cambios de forma, la guerra predatoria y el chamanismo; y he aquí, nuestro análisis recuerda que temas similares fueron representados entre las sociedades andinas verticales a lo largo de diferentes épocas. Las transformaciones de los chamanes y de los combatientes en animales salvajes, y al revés, es un tema andino profundamente arraigado, que ha sido reiterado desde los sacerdotes-jaguar de Chavin (Burger 1996) hasta los escuadrones militares de Huari, cada uno de los cuales se asociaba a la transformación en un animal o pájaro específico (Ochatoma Paravicino y Cabrera Romero
2001). Fue destacado también para el Aucaruna y el Inca por Guaman Poma que, a inicios del siglo XVII, bosquejaba la transformación a fines del siglo XV del Inca Otorongo (Inca jaguar) en un jaguar enemigo de los pueblos de las tierras bajas que intentaba conquistar ${ }^{40}$. Las transformaciones jaguar/humano de los guerreros-mineros del siglo XVII en Charcas fueron también documentadas por Bouysse-Cassagne (2004); en los desfiles y bailes altiplánicos del período republicano el tema de la transformación en jaguar se prologó utilizando pieles de jaguar (ver para el siglo XIX, Mercado 1991). Aun hoy en día, el tiempo lunar de los Chullpa irrumpe en nuestro tiempo solar cuando, de repente, la desasosegante aparición de un presagio bajo la forma de un animal o pájaro es interpretada como la persistencia de los Chullpas transformistas en los confines inestables del tiempo presente (Cereceda 1990). Ese tiempo otro, el tiempo de los guerreros enloquecidos, también nos espera a nosotros en los márgenes salvajes de un orden social construido para amansar los orígenes silvestres y sobrenaturales de la sociedad. Más aún, la gente se congrega regularmente e intenta recuperar para la sociedad algo de la energía creativa de los muertos inquietos por medio de rituales como el tinku y el carnaval (Harris 2000; Platt 1996), o por medio de su reencarnación como diabólicos fetos hambrientos lunares, que se transforman después de nacer en niños cristianos solares (Platt 2001).

La metáfora textil del control vertical andino puede ser aclarada por los estilos modernos de algunos tejidos como el diseño "mezclado" o "confundido" (chaxru) de los textiles de los vecinos de los Macha: los Jallq'a de Murumuru (Ravelo) y Chuquisaca (Cereceda et al. 2001). En cuanto a esto, la confusión fértil del mundo interno Jallq'a se expresa en una plétora de extrañas y heterogéneas bestias mitológicas (inspiradas a veces en las modernas etiquetas de publicidad) que destacan un contraste con las características bien ordenadas y luminosas de los tejidos del cercano Tarabuco. La luz tenue y engañosa del mundo de adentro Jallq'a contrasta con la luminosidad de esta tierra soleada de los Tarabucos, que, históricamente, fueron colonos del Inca asentados en los márgenes maiceros del imperio. En los valles Jallq'a también se encuentran colonos de los grupos del altiplano -Tinkipaya y hasta del Killaka y Karanqa altiplánicos-mezclados con campesino vallunos de Caracara o de Moromoro en una formación que también la llaman chaxru. 
(Mendoza y Patzi 1997; Pacheco 1994; $c f$. Platt et al. 2006:265-272). La transformación estética se halla en un diálogo constante con las transformaciones históricas y sociológicas.

El paralelismo entre los tejidos y el control vertical nos lleva a mirar las costuras numéricas de la organización social y política andina. En el tejer, sea cual fuere la apariencia final de "confusión" de los textiles, hay sin embargo una lógica subyacente a nivel de la técnica que proviene de los cálculos numéricos de la urdimbre y la trama y están al servicio de las preferencias estéticas de la tejedora. ¿Se puede afirmar lo mismo respecto a la organización social?

Apreciada a un nivel sociológico, la organización Macha se logra por medio de una combinación de un conjunto relativamente pequeño de principios que se superponen, como son: el centro generador con líneas radiantes o si no, alternativamente, en relaciones "sandwich" a lo largo de una compleja frontera (chawpi); en anidadas y superpuestas divisiones en dos, tres, cuatro, cinco y siete, con sus respectivos múltiplos, todas juntas constituyendo diferentes niveles de unidad; en las matrices arriba/ abajo, masculino/femenino, padre/hijo o cuñados, y otras dualidades multivalentes que se ramifican; en la "reciprocidad y la redistribución”, obligaciones festivas y de lex talionis, incluyendo la relación tributaria. Esto, considerando que el tinku y el ch'ajwa están asentados por sí mismos en una retórica de intercambio laboral recíproco ( $c f$. el chuqhunaku mencionado arriba): el ayni significa "relaciones de trabajo recíprocas" pero también "venganza"; y "devolver el ayni" (aynita kutichiy) se equipara, hoy, a muerto por muerto, que es uno de los objetivos de la guerra macha, tal como se dio en el siglo XVI (Santo Tomás 1951 [1551]). Una vez más, la guerra se presenta como integrando un aspecto de las prestaciones de trabajo colectivo de todos los miembros del ayllu, o de "servicios a cambio del acceso a la tierra". En efecto, el endocanibalismo y el exocanibalismo son dos aspectos mutuos ya que lo que es endoguerra a un nivel alto de segmentación es exoguerra a otro inferior. Combinados estos principios, configuran o "encuadran" una experiencia vivida que, por lo general, fluye flexiblemente a través de la "lógica de las formas" que caracterizó al pensamiento sociológico y moral andino (Platt 1978). Cuando el pasado salvaje de los antiguos Chullpas irrumpe en medio de todas las categorías de retención, y amenaza con disolver las fronteras ontológicas preexistentes (como ocurre en el chamanismo, en los augurios insólitos o en los ch'ajwas), ese humano y domesticado orden es cuestionado en sí mismo ${ }^{41}$.

Por consiguiente, "el punto de vista de la isla" nos lanza el reto de desenmarañar las formas que son inherentes a la complejidad social andina, sus transformaciones modulares y el alcance territorial. Tipifica las ambigüedades de la vida en medio del "desorden" del valle y la manera como las relaciones verticales son reproducidas y transformadas por vía de formas de violencia y sociabilidad negociadas. Las "islas" que son como "hebras rotas" están ocupadas por gente que deben cambiar las reglas del juego para lograr estabilizar su frágil existencia como "cabos sueltos". Se aferran a las posibles soluciones de su situación, entre las que están las exigencias que les imponen sus anfitriones. Sin embargo, las "islas" están de todas maneras obligadas a vivir en los márgenes ambivalentes del sistema segmentario y de las mitades. El ayllu menor vertical y sus integrantes cabildos apenas persisten a lo largo del tiempo, reafirmados en cada ceremonia semestral de pago del tributo, como un sitio relativamente no-ambiguo de pertenencia y lealtad.

Para finalmente enmadejar el ovillo: nuestro análisis ha mostrado como el "archipiélago vertical" de Murra fue en realidad (como él mismo lo previó) una maraña de lealtades en competencia, treguas, alianzas y enemistades. Hemos visto que esta situación fue, en sí misma, asimilada a la imagen de un tejido con sus hebras rotas y como, por lo tanto, esas hebras tenían que ser rehiladas en el poder dominante de cada vecindario. En realidad, los valles están "mezclados" a todos y cada uno de los niveles de la segmentación social, lo que no significa que no haya una salida para el aparente caos. Este "orden confuso" se expresa por medio de un juego de inversiones y ambigüedades que son, en el valle, las transformaciones del "orden dominante" implantado en la puna. Lo cual destaca un "punto de vista de las islas" específico, ubicado en los bordes internos de la sociedad del valle, mediador entre los puntos de vista de enemigos y amigos; y, a su vez, nos provee de nuevas maneras de pensar las tensiones y conflictos políticos inherentes a la posición de las islas en diferentes coyunturas históricas.

La transformación del tinku en ch'ajwa deletrea un importante desplazamiento en el alcance 
político y cosmológico de la guerra en los Andes: en los ch'ajwas lo que está en juego es la idea en sí misma de balance. Aquí el propósito es mover el fulcro, desplazando los bordes y sus hitos, conquistando y destruyendo la parte opuesta; arriesgándose a que lo mismo le pueda ocurrir a los del propio bando. Más aún, cuando las alianzas campesinas se vuelcan, no unos contra otros, sino hacia una abierta insurrección y rebelión contra el Estado y sus representantes locales, entonces las prácticas del cha'jwa se giran hacia las instancias locales de la administración y del gobierno. Así, por ejemplo, en la Guerra Civil boliviana de 1899 los indios del Norte de Potosí se enfrentaron al ejército constitucionalista del Presidente Severo Alonso en Tacarani. En los documentos se lee que: "se han encontrado trozos de soldados que fueron probablemente mutilados por los indios al calor de la refriega...", lo que es una clara referencia a las prácticas predatorias del cha'jwa (citado en Platt 1987b:316). El vuelco de los toros domésticos a bestias salvajes se da cuando el polo "no-humano" de la transformación coincide con el desplazamiento del ideal de equilibrio y balance entre las partes opuestas (tinku) hacia el deseo de matar, descuartizar y devorar los órganos de la presa (cha'jwa). $\mathrm{Y}$ estas ampliaciones de la escala de la violencia pueden constituirse en intervenciones históricas que mudan la vida de la sociedad mayor. Nos recuerdan que los desplazamientos del tinku hacia el cha'jwa (y viceversa) pueden ser correlacionados con una historia de los sucesos, incluyendo los períodos de tensión política y de enemistad duradera, y hasta de insurrección ${ }^{42}$.

Finalmente, ¿cómo debemos entender la dialéctica entre vecindad y verticalidad cuando su escala se amplía? ¿De qué manera las prácticas del asentamiento negociado que hemos mostrado, en una escala relativamente pequeña a través del trabajo de campo local, responden a las proyecciones del alcance más distante de la verticalidad altiplánica? Algunas respuestas, etnohistóricamente, han sido encontradas para los productores de maíz del siglo XVI de Tarabuco y Cochabamba: allí, los colonos lejanos que habían sido ubicados o confirmados por el Inka Wayna Qhapaq, fueron subsumidos localmente bajo la autoridad del señor regional dominante, ya sea de Aymuru, el señor de la federación de Yampara en Chuquisaca, o de Kuysara, Mallku de la federación Charka en Cochabamba (Platt et al. 2006). La escala segmentaria de las islas y sus alianzas que iba creciendo, como hemos visto anteriormente, conforme descendemos las vertientes orientales de los Andes hacia Mizque, se torna allí verdaderamente inmensa dado que las unidades de alianza y de oposición se convierten en los representantes locales de enteras federaciones y señoríos (wamani). En este caso, el acento puesto por Murra en que los Incas trascienden la motivación "puramente ecológica" del control vertical debería ser quizás matizada ya que la estrategia inca en la frontera sureste funcionaba más bien por medio de una ampliación de los mismos principios del alcance vertical en continua extensión (las tierras maiceras de Cochabamba, las plantaciones cocaleras de Chuquioma, etc.). Dichos principios estaban regidos por los intereses de proyectos estatales agrícolas grandemente ampliados y combinaban contingentes de trabajadores de turno (mitayos y mitimaes) salidos de casi todas las federaciones del altiplano al sur de Cusco, con silos, centros administrativos y guarniciones militares fortificadas (Platt et al. 2006; Wachtel 1981).

Más investigaciones serán necesarias para llegar a comprender la manera como las relaciones verticales fueron percibidas desde otros pisos ecológicos, desde otros "puntos de vista", como la chawpirana, ubicada entre el altiplano y los valles del Norte de Potosí; o cómo el "orden" del altiplano sufrió modificaciones cuando fue proyectado hacia las plantaciones de coca en los yungas de Pocona, Tiraque y Chuquioma en el siglo XV y $\mathrm{XVI}^{43}$; o aún, y finalmente, siguiendo las rutas de los invasores y colonos altiplánicos monte abajo, hacia el pie de monte y las tierras bajas, para orientar estas preguntas hacia grupos sociales ubicados en la ceja de selva, en los bosques y en las sabanas, y río abajo del Pequeño y del Gran Pará ${ }^{44}$.

Agradecimientos: Agradezco a Andrés Guerrero por la traducción de este trabajo, cuya versión en inglés se ha publicado en el Journal de la Société des Américanistes (Paris), Vol. 95-2, 2009. Agradezco a Isabelle Combès que me facilitó gentilmente una copia de la carta de Luis Ramírez (1528), publicada por Torres Revello en 1941. 


\section{Referencias Citadas}

Abercrombie, $\mathrm{T}$.

1998 Pathways of Memory and Power. Ethnography and History among an Andean People. Wisconsin University Press, Madison.

Absi, P.

2003 Los Ministros del Diablo. PIEB, La Paz.

Bouysse-Cassagne, $\mathrm{T}$.

2004 El Sol de Adentro: Wakas y Santos en las Minas de Charcas y en el lago Titicaca (siglos XV-XVII). Boletín de Arqueología PUCP 8. 59-97, Lima.

Burger, R.

1996 Chavin and the Origins of Andean Civilization. Thames and Hudson, London.

Cereceda, V.

1978 Sémiologie des tissus andins. Annales Économies, Sociétés, Civilisations 33(5-6):1017-1035.

1990 A partir de los colores de un pájaro. Boletín del Museo Chileno de Arte Precolombino 4:57-104.

2010 Semiología de los textiles andinos: las talegas de Isluga. Chungara Revista de Antropología Chilena 42:181-198.

Cereceda, V., J. Dávalos y J. Mejía

2001 A difference and a Meaning: The Textile Designs of Tarabuco and Jalq'a. ASUR. Sucre.

Cobo, B.

1964 [1660] Historia del Nuevo Mundo. Biblioteca de Autores Españoles t. XCII. Madrid.

Daillant, I. y V. Hirtzel

2010 La migración de un nombre: raíces de un equívoco etnológico ('Moxos', siglos XVI-XVII), en prensa.

Dransart, $\mathrm{P}$.

2002 Earth, Water, Fleece and Fabric: An Ethnography and Archaeology of Andean Camelid Herding. Routledge, London.

Flores Ochoa, J.

1979 [1977] Pastoralists of the Andes: The Alpaca Herders of Paratía. Institute for the Study of Human Issues, Philadelphia.

Fonseca Martel, C.

1973 Sistemas Económicos Andinos. Biblioteca Andina, Lima. Godoy, R.

1990 Mining and Agriculture in Highland Bolivia: Ecology, History and Commerce among the Jukumanis. University of Arizona Press, Tucson.

Guaman Poma de Ayala, F.

1980 [1615] El Primer Nueva Corónica y Buen Gobierno. Transcripción y edición de J.V. Murra, R. Adorno y G. Urioste. Siglo XXI, México.

Harris, O.

2000 To Make the Earth Bear Fruit. Institute of Latin American Studies, London.

High, M.

2008 Wolves, spirits and humans in the Mongolian goldmines. Ponencia presentada en el Coloquio sobre Humains, Animaux, Plantes et Choses: La notion de personne en Amazonie et Sibérie Contemporains. Musée du Quai Branly, June, Paris. Julien, C.

2006 Titu Cusi amenaza la guerra. En Ensayos de cultura virreinal latinoamericana., editado por U.J. Zevallos Aguilar, T. Kato y L. Millones. 79-98. Fondo Editorial de la Facultad de Ciencias Sociales de la Universidad Nacional Mayor de San Marcos, Lima.

Lakoff, G. y M. Johnson

1980 Metaphors We Live By. University of Chicago Press, Chicago.

Lorandi, A.M.

1978 Les 'horizons' andins: critique d'un modèle. Annales Économies, Sociétés, Civilisations 33(5-6):921-935.

Masuda, Sh., I. Shimada y C. Morris, compiladores

1985 Andean Ecology and Civilization. An Inter-disciplinary Perspective on Andean Ecological Complementarity. University of Tokyo Press, Tokio.

Maúrtua, V.M.

1906 Juicio de Límites entre Perú y Bolivia, t. IX. Imprenta de Henrich y Comp., Barcelona.

Mayer, E.

2004 [1985] The Articulated Peasant. Household Economies in the Andes. Westview, Boulder.

Mercado, M.M.

1991 Album de Paisajes, Tipos Humanos y Costumbres de Bolivia, 1841-1869. Banco Central de Bolivia, Archivo Nacional de Bolivia, Biblioteca Nacional de Bolivia, Sucre.

Mendoza, F. y F. Patzi

1997 Atlas de los Ayllus del Norte de Potosí. Territorio de los Antiguos Charka. Comisión Europea, Programa de Autodesarrollo Campesino (PAC), Potosí.

Murra, J.V.

1975 [1972] Formaciones Políticas y Económicas del Mundo Andino. Instituto de Estudios Peruanos, Lima.

2002 El Mundo Andino. Población, Medio Ambiente y Economía. Fondo Editorial Pontificia Universidad Católica del Perú e Instituto de Estudios Peruanos, Lima.

Murra, J.V., N. Wachtel y J. Revel, editores 1986 [1978] The Anthropological History of Andean Polities. Cambridge University Press, Cambridge.

Ochatoma Paravicino, J. y M. Cabrera Romero

2001 Ideología religiosa y organización militar en la iconografía del área ceremonial de Conchopata. En Wari. Arte Precolombino Peruano. Catálogo de Exposición Centro Cultural El Monte, Colección América, editado por L. Millones, pp. 173-211. Fundación El Monte, Sevilla.

Pachacuti Yamqui Salcamaygua, J. de Santacruz

1993 [1613] Relación de Antiguedades deste Reyno del Piru. Editado por Pierre Duviols y César Itier. Institut Français d'Études Andines/Centro de Estudios Regionales Andinos "Bartolomé de las Casas", Lima-Cusco.

Pacheco, D.

1994 Machas, Tinkipayas y Yamparas. CIPRES, Sucre.

Pärssinen, M. y A. Korpisaari, editores

2003 Western Amazonia-Amazônia Ocidental. Multidisciplinary Studies on Ancient Expansionistic Movements, Fortifications and Sedentary Life. Renvall Institute Publications 14, Helsinki.

Pease, F.

1985 Cases and variation of verticality in the southern Andes. En Andean Ecology and Civilization, an Interdisciplinary Perspective on Andean Ecological Complementarity, editado por Sh. Masuda, I. Shimada y C. Morris, pp. 141-160. University of Tokyo Press, Tokyo. 
Platt, T.

1978 Symétries en miroir. Le concept de yanantin chez les Macha de Bolivia. Annales Économies, Sociétés, Civilisations 33(5-6):1081-1107.

1982a Estado boliviano y ayllu andino: tierra y tributo en el Norte de Potosí. Instituto de Estudios Peruanos, Lima.

1982b The Role of the Andean ayllu in the reproduction of the Petty commodity regime. En Ecology and exchange in the Andes, editado por D. Lehmann, pp. 27-69. Cambridge University Press, Cambridge.

1983 Conciencia proletaria y conciencia andina: qhuya runa y ayllu en el Norte de Potosí. Historia Social Latinoamericana (HISLA) 2:47-73, Lima.

1987a Entre chíaxwa y muxsa. Para una historia del pensamiento político aymara. En Tres Reflexiones sobre el Pensamiento Andino, editado por Th. Bouysse-Cassagne, O. Harris, T. Platt y V. Cereceda, pp. 61-132. HISBOL, La Paz.

1987b The Andean experience of Bolivian liberalism. Roots of rebellion in Chayanta. En Resistance, Rebellion and Consciousness in the Andean Peasant World, editado por S. Stern, pp. 280-323. University of Wisconsin Press, Madison.

1991 [1984] Liberalismo y etnocidio en los Andes del Sur. Autodeterminación $\mathrm{N}^{\circ}$ 13. La Paz.

1992 Writing, shamanism and identity, or voices from AbyaYala. History Workshop Journal 34: 132-147 Special issue on Latin America, editado por B. Schwartz. Oxford University Press, Oxford.

1996 Los Guerreros de Cristo: Cofradías, Misa Solar y Guerra Regenerativa en una Doctrina Surandina (Siglos XVIIIñXX). Ediciones ASUR N ${ }^{\circ}$ 5-PLURAL, Sucre-La Paz.

1997 The sound of light: Emergent communication through Quechua shamanic dialogue. En Creating Context in Andean Cultures, editado por R. Howard-Malverde, pp. 196-226. Oxford Studies in Anthropological Linguistics, Oxford University Press, Oxford.

2001 El feto agresivo: Parto, formación de la persona y mitohistoria en los Andes. Anuario de Estudios Americanos LVIIIñ2. 225-265. Escuela de Estudios Hispano-Americanos, Sevilla.

2002 ìithout deceit or liesî. Variable chinu readings during a sixteenth-century tribute-restitution trial. En Narrative Threads: Accounting and Recounting in Andean Khipu, editado por J. Quilter y G. Urton, pp. 225-265. University of Texas Press, Austin.

2009 Tributo y Ciudadanía en Potosí, Bolivia. Consentimiento y libertad entre los ayllus de la Provincia de Porco, 18301840. En Dinámicas de Poder Local en América Latina, Siglos XIX-XXI, editado por P. García Jordán, pp. 109163. Publicaciones de la Universitat de Barcelona / Taller de Estudios e Investigaciones Andino-Amazónicos, Barcelona.

Platt, T., T. Bouysse-Cassagne y O. Harris 2006 Qaraqara-Charka. Mallku, Inka y Rey en la Provincia de Charcas. Historia Antropológica de una Confederación Aymara, con el aliento de Thierry Saignes, Institut Français d'Études Andines/Plural Editores/University of St Andrews/ University of London/Fundación Cultural del Banco Central de Bolivia, La Paz.

Presta, A.M., compiladora

1995 Espacios, Fronteras, Etnias. ASUR 4, Sucre.
Renard-Casevitz, F.M.

2002 Social forms and regressive history: from the Campa cluster to the Mojos and from the Mojos to the Landscaping terrace-builders of the Bolivian savanna. En Comparative Arawakan Histories: Rethinking Language Family and Culture Area in Amazonia, compilado por J. Hill y F. Santos Granero, pp. 123-146. Routledge, London.

Renard-Casevitz, F.M., T. Saignes y A.C. Taylor 1988 Al Este de los Andes: Relaciones entre las Sociedades Amazónicas y Andinas entre los Siglos XV y XVII. Ediciones Abya-Yala e Instituto Francés de Estudios Andinos, Quito.

Saignes, T.

1978 De la filiation a la residence: les ethnies dans les vallées de Larecaja. Annales Économies, Sociétés, Civilisations 33(5-6):1160-1181.

1985 Los Andes Orientales: Historia de un Olvido. IFEA/ CERES, Lima/Cochabamba.

Santo Tomás, D.

1951 [1551] Lexicon, o Vocabulario de la Lengua General del Peru. Universidad Mayor de San Marcos, Lima.

Santoro, C.M., T.D. Dillehay, J. Hidalgo, D. Valenzuela R., Á.L. Romero G., F. Rothhammer y V.G. Standen

2010 Revisita al Tercer Caso de verticalidad de Murra en la costa de los Andes Centrales y Centro Sur. Chungara Revista de Antropología Chilena 42:325-340.

Serulnikov, S.

2006 Conflictos Sociales e Insurrección en el Mundo Colonial Andino. El Norte de Potosí en el Siglo XVIII. Fondo de Cultura Económica, Buenos Aires.

Stobart, $\mathrm{H}$.

2006 Music and the Poetics of Production in the Bolivian Andes. Ashgate Publishing Limited, Aldershot.

Tandeter, E.

1992 Coacción y Mercado: la Minería de la Plata en el Potosí Colonial, 1692-1826. Centro de Estudios Regionales Andinos Bartolomé de Las Casas, Cusco.

Torre Revello, J., editor

1941 Documentos Históricos y Geográficos Relativos a la Colonización Rioplatense (Tomo 1). Talleres S.A. Casa Jacobo Peuser Ltda., Buenos Aires.

Torrico, C.

s/f El simbolismo de los costales en el ayllu Macha. Texto inédito.

Troll, C.

1968 Geo-ecology of the mountainous regions of the tropical Americas. Colloquium Geographicum 9, Bonn.

Uzendoski, M.A.

2004 The Horizontal Archipelago. The Quijos/Upper Napo Regional System. Ethnohistory 51:317-357.

Véricourt, V. de

2000 Rituelles et Croyances Chamaniques dans les Andes Boliviennes. Les Semences de la Foudre. L'Harmattan, Paris.

Viveiros de Castro, E.

1998 Cosmological deixis and Amerindian perspectivism. Journal of the Royal Anthropological Institute 4:469-488.

Wachtel, N.

1981 Los mitimas del valle de Cochabamba: la política de colonización de Wayna Qhapaq. Historia Boliviana 1(1):2157, Cochabamba. 


\section{Notas}

1 A la vuelta de mi primer trabajo de campo en Macha en septiembre de 1971, pasé por Ithaca NY para visitar a John Murra, y di un seminario sobre el concepto de yanantin y el archipiélago vertical de Macha en el jardín de su casa en Dryden Road. Empecé a poner por escrito un texto sobre el dualismo y la cuatripartición en Macha en Londres a fines de 1971, pero no lo terminé hasta 1975, cuando trabajaba en el Museo de Azapa de la Universidad del Norte, Arica. Salió primero como Cuaderno de CIPCA (La Paz) en 1976, y después, revisado, en el número andino de Annales (Paris 1978; versión en inglés de Cambridge 1986) editado por John Murra, Nathan Wachtel y Jacques Revel (1986 [1978]). El trabajo que aquí presento sobre las "islas" del archipiélago, por otra parte, fue elaborado en 1977 para presentación oral en una reunión del Grupo "Avances" realizada en el Archivo de La Paz, y fue desarrollado para un seminario andino con John Murra llevado a cabo en el London School of Economics en 1985. Después de la muerte de John en 2006, se retomó el trabajo aún inédito para este número homenaje de Chungara.

2 Murra también se preguntaba si las sociedades de la costa podían haber tenido "islas" en el altiplano (lo que ha sido demostrado: Masuda et al. 1985; Santoro et al. 2010); sin embargo, no contempló la posibilidad de que los señoríos amazónicos las tuvieran por igual en las vertientes orientales de los Andes. Ver Renard-Casevitz 2002; $c f$. Daillant y Hirtzel (2010).

3 En 1972, el ejemplo que ofrecía Murra de una "isla estatal" fueron los productores de coca en los valles tropicales de Songo, más abajo de La Paz, un grupo yunga-hablante del pie de monte carente de tierras en el altiplano, aunque con implantaciones aymara-hablantes. Probablemente fueron incorporados en el imperio Inca con el propósito específico de producir coca para el Estado. Diversas maneras de incorporación al Tawantinsuyu de los grupos de las franjas tropicales del pie-de-monte oriental han sido estudiadas en Saignes 1985 (Ch.1); Renard-Casevitz et al. 1988; y Platt et al. 2006).

4 Los arqueólogos andinos distinguen -generalmente con excesiva linearidad- entre períodos de consolidación y expansión del Estado (Horizontes) y períodos intermedios o formativos, cuando prevalecen sociedades regionales cada una en un estado de guerra con sus vecinos. Ver Lorandi 1978. En realidad, la guerra puede continuar regionalmente en los márgenes del alcance real de cada Estado, aun si pudo existir la tendencia, ya mencionada, a transformarla en un "juego" ritualizado o en competición en los momentos del mayor control estatal.

5 La documentación colonial temprana entre 1579 y 1619 confirma que el archipiélago valluno Macha es un ejemplo de estabilidad de larga duración que remonta hasta los tiempos prehispánicos. Ver Platt et al. 2006 (Parte IV, Documento 8 , con sus apéndices) y los mapas del asentamiento valluno de Macha (Platt 1996, Mendoza y Patzi 1997, y Figura 1 del presente artículo).

6 Franklin Pease (1985) reconoció que territorios discontinuos en formaciones orográficas verticales pueden constatarse en muchas partes del mundo (incluso Europea occidental) y en diferentes periodos sociales e históricos.

7 Véase George Lakoff y Mark Johnson 1980. Para estos autores, la guerra es un claro ejemplo de la metáfora por la cual vive el "occidente" capitalista moderno (se puede aplicar a una discusión, o a un discurso mercantil), aun si la guerra y la violencia son también poderosas -como experiencia, metáfora y simbolismo religioso- en muchas otras "sociedades guerreras", incluyendo a los Macha.

8 Un borrador de una parte de este artículo, presentado en un seminario dedicado al trabajo de Murra en la London School of Economics en 1986, lo titulé "Guerra y alianza en una plantación andina de fresas".

9 Los "tomadores de mujeres" (wife-taking affines) se la "llevan", tal como lo hace el cóndor a una muchacha, en un muy conocido cuento, a su nido en las cumbres rocosas (en quechua: thapa, que es también un nombre ritual de la casa familiar, o del "hogar"). El cuñado se representa como cóndor en la ceremonia rural de matrimonio, lo que significa un reconocimiento del sustrato salvaje que hay en el tráfico sexual humano, en paralelo a los combates de toros. En cuanto a los cóndores y toros como expresión de la masculinidad andina, véase Harris 2000.

10 Para la edad de los Aucaruna, Guamán Poma describe estas transfiguraciones como sigue: "se volvieron grandes capitanes y valientes príncipes de coraje puro, decían que en el combate se convertían en leones [pumas], tigres [jaguares], zorros, águilas y gatos salvajes, y, así, hasta hoy en día, sus descendientes se llaman otorongos [jaguar], atoc [zorro], condor anca [águila], y vientos usco y acampana, en pajaro huayanay, culebra machacuay, serpiente amaru -y así sus nombres ancestrales y sus armas son llamados según otros animales que sus ancestros ganaron en la batalla que tuvieron..." citado en Platt 1987a. En cuanto a las transformaciones chamánicas en cóndor en Macha, hoy en día, véase: Platt 1996, Véricourt 2000; para la experiencia de transformación de los mineros en el actual Potosí, Absi 2003; cf. Bouysse-Cassagne 2004, sobre las transformaciones de los mineros-guerreros en jaguar durante el período colonial temprano, en un contexto en que prevalecía ampliamente el culto chamánico del jaguar tanto en el altiplano como en las tierras bajas. Sobre la vinculación de las minas con el rayo y la guerra, ver Platt et al. 2006 (Parte I).

11 San Marcos fue fundada por los visitadores, los curas y los reducidores que estaban encargados en los 1570s de ejecutar el programa de reasentamiento del virrey Toledo; remplazó al asentamiento prehispánico de Pichibisa. San Pedro de Macha fue el "pueblo de reducción" de los Macha en la puna (ver Platt et al. 2006 (Parte IV). La visita de 1619 de San Marcos revela una interdigitación y distribución de los ayllus, similar a la que se puede constatar hoy en día (ver Platt 1996, Mapa 1; Platt et al. 2006:571-574)

12 En 1971, el viejo kuraka de Macha Anansaya, don Agustín Carvajal, me relató que tuvo un sueño: había cóndores que revoloteaban sobre él; y el yachaj (chamán) le había dicho que ese sueño significaba que no había ido a cumplir su sacrificio en la montaña Chiuquru, ubicada a la entrada del valle, y que si no cumplía caería enfermo y moriría. En un cuento macha muy conocido, los cóndores dan las vueltas sobre una muchacha escondida en un q'ayru (un agujero cubierto para conservar papas) y la dejan apenas en huesos. El sueño del kuraka fue igualmente interpretado como una amenaza de muerte por los cóndores, que son los espíritus de las montañas, o jurq'us. 
13 En los valles de la provincia de Charcas esta ambigüedad fue políticamente manipulada por los dirigentes sindicales en los años 1970, con el argumento que los campesinos de los valles debían separarse de la puna y constituir sindicatos campesinos del valle en lugar de conservar sus lazos con la parcialidad, los grupos de parentesco de los ayllus y las autoridades de la puna. Ver Platt (1982a). Hoy parecen haber logrado su objetivo, ver Mendoza y Patzi 1997.

14 La fiesta de San Marcos está descrita en Platt 1996. En 1971, una melodía de charango conocida como walli mayu (río de valle) fue la que se utilizó en la fiesta de la Cruz del 3 de mayo (charango es una pequeña guitarra, con cuerdas dobles, que utiliza tradicionalmente como caja de resonancia el carapacho de un armadillo). Pasada la fiesta de la Cruz en San Pedro de Macha, los llameros inician su periplo hacia abajo rasgando sus charangos mientras caminan y acompañan a sus llamas que siguen a la llama delantera. Para un estudio amplio sobre la música estacional de Macha, referido a la estancia de Cayanquira (Cabildo Titiri, Ayllu Taphunata, mitad Alasaya), ver Stobart 2006.

15 La organización decenal en Macha se debe probablemente a la influencia Inca. La información documentada sugiere una relación estrecha entre el Inca Wayna Qhapaq y los señores regionales de Macha y Pocoata. Ver Platt et al. 2006 (Documento 16 y el "Ensayo de Interpretación"). La referencia más temprana a los cabildos en tanto grupos territoriales proviene del período republicano (ver Platt 2009).

16 En 1996 Fernando Mendoza y Félix Patzi intentaron cartografiar la distribución física de estos grupos como parte de un proyecto cartográfico financiado por el "Programa de Autodesarrollo Campesino" (PAC) de la Comunidad Europea (ver Mendoza y Patzi 1997:94, 116). Por mi parte, pude reunir información en 1970-71 (Platt 1996, Mapa 1). Hay que recordar, además, que la cartografía por satélite desconoce por completo la tradicional flexibilidad de los límites de las tierras de los ayllu, vinculada a las variaciones políticas y demográficas locales (ver Platt 1982b).

17 Sobre el impacto de la Ley de Exvinculación (1874) y un análisis de la manera en que las tierras de un originario pueden ser progresivamente fragmentadas y repartidas entre otras categorías de tributo como, por ejemplo, los agregados y forasteros (kantu runas), ver Platt 1982a, 1982b; cf. Harris 2000 para los Laymi, y para los Jukumani, Godoy 1990.

18 Manta: del aymará mantaña: "entrar". En otros lugares, otras palabras ponen énfasis en diferentes características semánticas de estas tierras, como el hecho de que son una concesión temporal de la comunidad (mañay) o sobre la naturaleza rotativa de su cultivo (muyuy). Cf. Fonseca Martel 1973; Harris 2000.

19 Véase, por ejemplo, copia de una carta, consultada en el Archivo de Alasaya (ver Platt 1992), que el kuraka de Alasaya, Santiago Carvajal (hijo de Agustín Carvajal), dirigió a su contraparte de Majasaya, en la que rehúsa prestar ayuda a los Majasaya que se encontraban en un conflicto con sus vecinos Pocoatas.

20 En el siglo XVI esas tierras fueron cultivadas por 10 mitayos (camayos), uno para cada uno de los 10 ayllus menores, como plantaciones colectivas menores de los ayllus. Las "tierras de común" de Carasi fueron consideradas como las más ricas de Macha. Sin embargo, luego de la Visita toledana de 1573 (que ratificó la propiedad colectiva de
Macha), los españoles se apoderaron de esas tierras y nunca fueron devueltas a pesar de las protestas reiteradas de los Macha ante la Audiencia de Charcas. Ver Platt et al. 2006 (Parte IV, “Tierra").

21 Véase Pacheco (1994); y Platt et al. (2006) donde se argumenta que en el siglo XVI Laymi fue parte de la federación de Qaraqara aunque concentrado en la mitad superior (Anansaya) de Chayanta y dependiendo de las autoridades dominantes en Macha y Pocoata. Quizás eran colonos Qaraqara enviados a compartir el acceso a las minas de estaño y oro de Llallagua y Amayapamba, con la mitad inferior (Urinsaya) de Chayanta, que dependía de la capital de la federación Charka en Sacaca. Si así fuera, la leyenda que se escuchó podría reflejar una situación histórica cuando los Laymi, Pocoatas y Machas, pertenecían todos a la misma jurisdicción asentada en Macha.

22 La insistencia en el número 12 también coincide con la importancia que se da a esa cifra en los contextos rituales, cuando las libaciones son derramadas para Tata chunkaiskayniyuj, "el Padre Doce". En la puna me relataron que doce era el número ideal de niños en una familia, que nuestros dedos de los pies y de las manos deberían idealmente comprender en cada individuo dos grupos de seis, que había doce montañas que rodeaban a la aldea, que el número de ayllus debía ser doce, que había doce milagros que debían reverenciarse en los doce santuarios dentro y fuera de la región del Norte de Potosí. La importancia del doce podría asociarse a la historia cristiana de los doce apóstoles, aunque también podría reverberar con un período anterior, el de la imposición por el Inca de la organización decimal sobre una anterior organización duodecimal. Cf. Platt 1983, 2002; y Platt et al. 2006.

23 Desde entonces, Mendoza y Patzi (1997) han cartografiado otras islas en el cantón San Marcos, además de las que pude recopilar en 1971.

24 También en la puna se encuentran a veces subdivisiones dentro de los cabildos; ver, p.ej. Stobart (2006:140) para la división de la estancia de Cayanquira (Cabildo Palquyu, ayllu menor Taphunata, mitad Alasaya) entre las secciones de "arriba" y de "abajo".

25 Esta distinción es verificada también por Enrique Mayer (2004).

26 Compárese con el esclarecedor informe del Gobernador Diez Canseco sobre los usos en el pago del tributo en la provincia de Chayanta durante el período republicano temprano (citado en Platt 1991:10-12).

27 Antes de que fuera abolido el tambo en Macha, durante los años 1970, el sistema de cargos se había vuelto complicado por la creación de nuevos cantones; es así que los Majapichas y los Alapichas tenían un tambo separado, en Qulqapujyu, cerca de Chayrapata y Ocurí, y no participaban en el sistema de turnos en el cantón Macha. De igual manera, los cabildos de Rosario (AlaQuyana) y Aullagas (Waraqhata) pertenecían al cantón de Colquechaca, la capital de la moderna provincia de Chayanta. Por informaciones del kuraka de Alasaya en 1971, el orden dentro de los términos del cantón Macha (Alasaya) era el siguiente: AlaQuyana (3 meses), Taphunata y Waraqhata (3 meses) y Sullkhawi (3 meses). Se proveía seis hombres para cada turno de acuerdo a otra serie de turnos fijados al nivel de los cabildos subsidiarios. Por ejemplo, los seis hombres de AlaQuyana (excluyendo Rosario) fueron escogidos de la 
siguiente forma: Pichichhua (2), Yuraqari (2), Pumpuri y Chuqiqayara (1, en turno alternado), y Kuimuri y Ayuma ( 1 , en turno alternado).

28 En cuanto a los K'ultas de la puna, véase Abercrombie 1998.

29 Vera, que significa verdadera, se pronuncia wila en aymara, lo cual significa sangre (ver Platt 1996).

30 Cassandra Torrico ha analizado los grupos del carnaval y las formas de semáforo, usando banderas, que despliegan las tropas de baile femeninas para comunicar la rivalidad entre las mitades (comunicación personal, s/f).

31 Los antecedentes de este conflicto y las contradicciones que acarreaba la afiliación vertical para el sistema administrativo republicano pueden observarse en un documento de 1887 (Archivo Histórico de Potosí, Prefectura Departamental Expedientes 7475), en el que los Alasaya del cantón San Marcos aparecen denunciando a los k'ultas de "la provincia de Paria, Departamento de Oruro" por "usurpar" sus tierras bajo el pretexto de que los "Gobernadores antiguos" de Macha les hubieran dado las tierras a cambio de "250 pesos". Es una clara referencia al mismo suceso cuya versión oral escuché en 1971. Los orígenes de esta isla de K'ulta son probablemente coloniales.

32 La viuda puso un recurso ante el Secretario de Justicia y Conflictos de la Federación Sindical Campesina en Banduriri (provincia de Charcas); pero la Federación argumentó la posición de los Sullkhawis diciendo que la viuda nunca debió abandonar el lote si esperaba que la Reforma Agraria la apoyase.

33 El pago del tributo a la puna casi desapareció durante un tiempo en los valles Macha, pero fue posteriormente reactivado como una defensa campesina del sistema tradicional. Ver Platt 1982a sobre los niveles fluctuantes del cobro del tributo entre 1951 y 1980, y la denuncia de los Macha contra el presidente Paz Estenssoro, el líder MNR local Hugo Reinaga y la Reforma Agraria de 1953. Don Santiago Carbajal, kuraka de Alasaya, afirmó que la revolución MNR había en realidad sido una batalla entre la hacienda parti y la tasamanta parti; lo cual implicaba que el propósito de derrotar a los hacendados fue hacer que sus tierras pudieran revertir al régimen ayllu; una vieja reivindicación que data de las insurrecciones del siglo XVIII y aún antes, y que ha seguido fuerte a lo largo del período republicano.

34 La complejidad y cantidad de estos niveles en el período prehispánico y de la temprana colonia fue desde luego mucho mayor; abarcaba a toda la provincia de Charcas y, aún más, hasta todo el Qullasuyu al sur de Cusco. Como es lógico, el cálculo sociológico pensado a esta escala se vuelve más elaborado, como lo veremos más abajo. Ver también Platt et al. 2006 ("Ensayo de Interpretación"; y la Parte V).

35 También se hallaron estas casas ápices a nivel de los tributarios comunes y corrientes y, durante el período republicano temprano, todavía podían ser re-fundadas durante cada visita o revisita (Platt 1982a, 1982b).

36 El infratexto "diabólico" del simbolismo del Cristo crucificado había sido observado a comienzos del siglo XVII por el arzobispo visitador Bernardino de Cárdenas, cuando extirpaba idolatrías entre los mineros de Potosí. Ver Bouysse-Cassagne 2004. En las áreas rurales alrededor de Potosí todavía se puede encontrar esta doble lectura del Cristo crucificado (Platt 1996).
37 Ver, por ejemplo, la organización de actos de resistencia desde los valles a la implementación de la Primera Ley de Reforma Agraria en el Norte de Potosí, analizada en Platt (1987b).

38 Cabe recordar que, en 1970-71, el Estado boliviano tenía otras preocupaciones antes que garantizar los lazos verticales entre puna y valles, a pesar de que los ayllus podían invocar pruebas de los períodos colonial y republicano que "establecían" la distribución vertical por medio de rituales de confirmación (amojonamientos, revisitas, etc.) que han sido repetidamente documentados.

39 En Macha, cerca del lugar de asentamiento "chullpa", me indicaron un "cementerio chullpa" constituido de pozos poco profundos amojonados con piedras que, en la superficie, forman un cuadrado; dentro del pozo una calavera sin cuerpo (¿una cabeza trofeo?) yace acompañada de cerámicas y ofrendas.

40 La transformación del Inca Otorongo en jaguar (otorongo) cuando combatía los grupos de las tierras bajas fue re-actuado (re-enacted) por Tito Kusi Yupanki en 1561 en una carta de amenaza dirigida al corregidor del Cusco (Julien 2006).

41 En cuanto a la "lógica de las formas", véase C. Lévi-Strauss en Du miel aux cendres, citado en Platt 1978. Dicha lógica no excluye, sin embargo, la simultánea transformación de los guerreros en una expresión de las fuerzas "naturales", lo que advierte sobre una tensión permanente en los Andes entre las perspectivas del desorden y aquellas de la lógica formal.

42 Por ejemplo en Mongolia, se ha estudiado que el desvanecimiento de las fronteras entre lo animal y lo humano es un resultado reciente; proviene de la irrupción de la minería aurífera que ha enfurecido a los espíritus y ha conducido a la aparición de los hombres-lobo, cuando antes las categorías de humano y animal se mantenían claramente separadas (High 2008).

43 En cuanto a los asentamientos prehispánicos y temprano coloniales de las diferentes federaciones de Colla y Charcas en los valles maiceros de Cochabamba y en los yungas de Tiraque productores de coca, tanto como en los alrededores de los enclaves mineros en la puna de Chayanta (estaño y oro) y Porco-Potosí (plata-plomo) (Platt et al. 2006). Aquí también, las lejanas afiliaciones fueron subsumidas dentro de las estructuras locales de autoridad.

44 El Amazonas y el Paraná. Sobre la existencia de enclaves de los Charka y de los Pakasa en las tierras bajas del oriente durante el siglo XVI, ver, p.ej., la entrada de Francisco de Ángulo al Chapare en 1588, publicada parcialmente por Maúrtua 1906 (t. IX). Aunque las alianzas en las que los Pakasa participaron no han sido aclaradas, se dice que habrían estado involucrados en combates con el Inca y con sus vecinos de las tierras bajas. Sobre la presencia Inca en las tierras bajas del oriente en Las Piedras, cercanas al horcajo del río Beni y Madre de Dios (cerca de Riberalta), ver Pärssinen y Korpisaari 2003. Se ha sugerido que la palabra "Carcaraes", utilizada por algunas fuentes atlánticas para referirse a los "Caracaras" [Qaraqaras] de Macha y Chaquí, tal vez puede estar presente en el nombre del río "Carcarañal, lo que señalaría una lejana "isla" de la misma gente en la unión de los ríos Carcarañal y Paraná, cerca del Fuerte Santo Espíritu de Cabot. Véase la carta de Luis Ramirez (1528), publicada en Documentos históricos y geográficos... (Torres Revello 1941) (Tomo I, p.91, Documento No 16), copia de esta carta me fue facilitada por Isabelle Combès. 


\section{APÉNDICE}

\section{Clave del Mapa (Figura 1) Según Ayllu Máximo, Mitad, Churi Ayllu y Cabildo}

Las tierras de Macha en el Departamento de Chuquisaca (Provincia de Yamparez) han sido omitidas: requieren investigación y mapeo). Los números se refieren a los números en el Mapa (Figura 1). Algunos datos son aproximados, y otros seguramente necesitarán corrección. Un mapeo definitivo requerirá la colaboración sobre el terreno de las autoridades tradicionales de Macha, cuya jurisdicción en los valles ahora está cuestionada por la aplicación de la Ley de Participación Popular, junto con más trabajo en el Archivo Histórico de Potosí, donde existen los levantamientos realizados en el siglo XIX, no incorporados ni en este trabajo ni en el de Mendoza y Patzi (1997). Sin embargo, los datos comentados en este texto son seguros en cuanto representan información cualitativa sobre disputas candentes recogida entre los pobladores de San Marcos de Miraflores.

MP = Mendoza y Patzi 1997.

\section{K'ULTA}

- Ayllu Kullana. 1. Llanquiri.

Aunque en 1971 algunos K'ultas de Llanquiri protestaron que debían sus tributos y servicios a Santa Bárbara de Culta (pueblo del Departamento de Oruro, situado sobre la frontera con las tierras altas de Macha, ver Abercrombie 1998), otros eran de la opinión que deberían reorientar sus prestaciones hacia Macha y unirse con los AlaQuyanas de Lluchhu. En 1997, MP sugieren que este proceso se había consumado: en su Atlas representan a los K'ultas de Llanquiri como "Ayllu AlaQuyana" de Macha. Se requiere más investigación sobre este punto.

\section{MACHA}

\section{Mitad Alasaya}

- Ayllu AlaQuyana

Cabildo Ayuma. AlaQuyanas de 2. Lluchu (anexo) y 3. Chayta.

Cabildo Chuquiqayara. n/d.
Cabildo Kuymuri. AlaQuyanas de Kuymuri 4, 5, 6 .

Cabildo Pichhichhua. AlaQuyanas de 2. Lluchu y 3. Chayta.

Cabildo Pumpuri. AlaQuyanas de 2. Lluchu y 3. Chayta.

Cabildo Rosario. $\mathrm{n} / \mathrm{d}$.

Cabildo Yuraqari. AlaQuyanas de 7. Amutara.

En Lluchhu y Chayta los AlaQuyanas de los cabildos de Ayuma, Pichhichhua y Pumpuri son mezclados (chajrusqa).

\section{- Ayllu Sullkhawi}

Cabildo Challwiri

Cabildo Salinas

Cabildo Qharipurqu

Cabildo Kiuja

Cabildo Tanki

No hay datos sobre los cabildos del valle, donde se distinguen toponímicamente entre los Jatun Sullkhawis ("Gran Sullkhawi”) de Ichurata (8) y los Juchuy Sullkhawis ("Pequeño Sullkhawi") de Chharichhari (9), sin especificación del cabildo.

- Ayllu Waraqhata

Cabildo Awllakas

Cabildo Kantakanta

Cabildo Kañuquta

Cabildo Usquria

Cabildo Waylloma

No hay datos sobre los cabildos del valle, solo distinciones toponímicas entre los Waraqhatas de Payluta (10), Paria (11), Samuma (12) y Sayaqa (13), sin especificación del cabildo.

\section{- Ayllu Taphunata}

Cabildo Titiri

Cabildo Palquyu

Cabildo P'uqira

No hay datos sobre los cabildos del valle, donde se distinguen toponímicamente entre los Taphunatas de Chawarani (14 MP; TP: Qolqapampa) y Karpani (15), sin especificación del cabildo.

\section{- Ayllu Alapicha.}

Cabildo Tuqhuqari

Cabildo Ch'iaraqi 


\section{Cabildo Lurukachi \\ Cabildo Turku \\ Cabildo Qullpa}

[Cabildo Jamach'iri: MP]

No hay datos sobre los cabildos del valle, donde se distinguen toponímicamente entre los Alapichas de Urqhapampa (16), Altu Luma (17; MP), K'aspikancha (18), Janq'uma (19), sin especificación del cabildo.

\section{Mitad Majasaya}

- Ayllu MajaQuyana

\section{Cabildo Kutañisu}

Cabildo Waykuta

Cabildo Chajrani

Cabildo Jiruq'uma [no en MP].

Cabildo Umajila (o Jatun Qullana).

Cabildo Yuqhuna [MP lo asigna a Sullkhata].

Cabildo Phurki [MP lo asigna a Majapicha].

Pocos datos sobre los cabildos del valle, donde

se distinguen entre los MajaQuyanas de Qayanqa (20), Yuqhuna (cabildo y topónimo: 21), Triguira (22), Mathariri (23), Chuquipampa (24), Lluchhu (cabildo Waykhuta: 25).

\section{- Ayllu Sullkhata}

Cabildo Juluch' $i$

[Cabildo Yuqhuna: MP]

Pocos datos para los cabildos del valle, se distinguen por topónimos, p.ej. Sullkhatas de Ch'alloma (26), Waramaya (27), inciertos $(28,29)$.

\section{- Ayllu Kunthawata}

Cabildo Llust'aqi

[Cabildo Q'illuq'asa: MP]
Solo un cabildo identificado en el valle, los demás por topónimos: Kunthawatas de Kuñurani (30), Durasnillo (31), Llust' aqi (32), incierto (33), Wankarani (34).

\section{- Ayllu Wakhuata}

Cabildo Milluri

Cabildo Pumpuri

Cabildo Llust'aqi

No hay datos para los cabildos del valle, solo topónimos: Wilakota (35: jatun wakhuata, "Gran Wakhuata"), Ilili (36: churi wakhuata, "hijo Wakhuata"), Sikuta (37: churi wakhuata).

- Ayllu Majapicha

Cabildo Tumaykuri

Cabildo Rukuruku

Cabildo Pichikachi

Cabildo Lluchhu

Cabildo Milluni

[Cabildo Tarwaki: MP]

[Cabildo Pastupampa: MP]

[Cabildo Phurki: MP]

[Cabildo Chayrapata: MP]

[Cabildo Jut'i: MP]

No hay datos para los cabildos del valle, solo topónimos: p.ej., Waranqa (38), Qatachilla (39).
40 Chuqi Churu
41 Lupi
42 Niq'iri
43 Umu Pampa
44 Ch'uñu Jarana 